U.S. ARMY CERL LIBRARY

OCT 3 \% 2000
Evaluation of Three-Component Magnetic Sensors for Delineation and Identification of UXO

Janet E. Simms, Lewis B. Smithhart, and Dwain K. Butler 
The contents of this report are not to be used for advertising, publication, or promotional purposes. Citation of trade names does not constitute an official endorsement or approval of the use of such commercial products.

The findings of this report are not to be construed as an official Department of the Army position, unless so designated by other authorized documents. 


\section{Evaluation of Three-Component Magnetic Sensors for Delineation and Identification of UXO}

by Janet E. Simms, Dwain K. Butler

Geotechnical Laboratory

U.S. Army Engineer Research and Development Center 3909 Halls Ferry Road

Vicksburg, MS 39180-6199

Lewis B. Smithhart

Information Technology Laboratory

U.S. Army Engineer Research and Development Center 3909 Halls Ferry Road

Vicksburg, MS 39180-6199

Final report

Approved for public release; distribution is unlimited 


\section{Engineer Research and Development Center Cataloging-in-Publication Data}

Simms, Janet E.

Evaluation of three-component magnetic sensors for delineation and identification of UXO / by Janet E. Simms, Dwain K. Butler, Lewis B. Smithhart ; prepared for U.S. Army Corps of Engineers.

32 p. : ill. ; 28 cm. -- (ERDC ; TR-00-6)

Includes bibliographic references.

1. Explosives, Military -- Detection. 2. Ordnance -- Detection. 3. Magnetism. 4. Geophysics Testing. I. Butler, Dwain K. II. Smithhart, Lewis B. III. United States. Army. Corps of Engineers. IV. Engineer Research and Development Center (U.S.) V. Geotechnical Laboratory (U.S.) VI. Information Technology Laboratory (U.S.) VII. Title. VIII. Series: ERDC TR; 00-6. TA7 E8 no.ERDC TR-00-6 


\section{Contents}

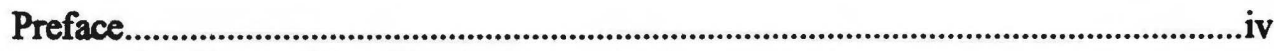

Conversion Factor, Non-SI to SI Units of Measurement .............................................v

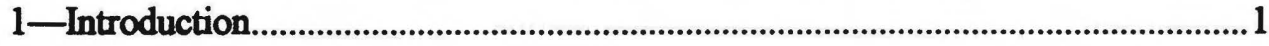

2-Theoretical Magnetic Models..........................................................................3

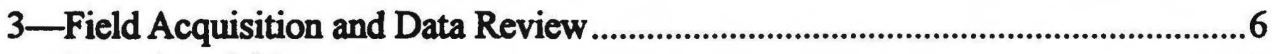

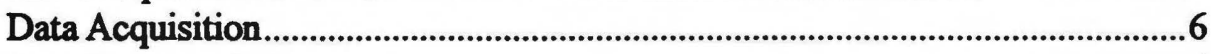

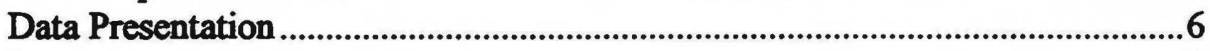

Sensor Levelness......................................................................................................9

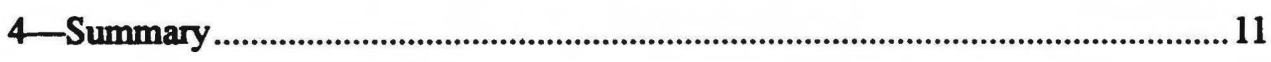

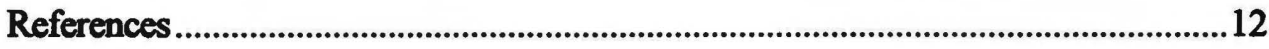

Figures 1-11

SF-298 


\section{Preface}

A three-component magnetometer study was undertaken as part of the Work Unit "Innovative Geophysical Technologies for Enhanced Buried UXO

Discrimination" (AF25, 6.2), funded by the U.S. Army Engineer Research and Development Center (ERDC), under the Environmental Quality Technology (EQT) Program. The data were acquired during the period January through April 2000 by personnel of the Geotechnical Laboratory (GL) and Information Technology Laboratory (ITL), ERDC, Vicksburg, MS. This was a preliminary investigation to determine if the additional information provided by three-component magnetometer sensors can improve the discrimination and identification capabilities currently achieved using total magnetic field magnetometers. Dr. M. John Cullinane was Program Manager, USAERDC, for the EQT Program.

This report was prepared by Dr. Janet E. Simms, Geotechnical, Earthquake, and Geosciences Division (GEGD), GL. Field data were collected by Dr. Simms and Mr. Lewis B. Smithhart, Operations Branch, ITL. Geophysical data analysis was performed by Dr. Simms. The work was performed under the direct supervision of Mr. Donald Yule, Acting Chief, Geotechnical, Earthquake, and Geophysics Branch, GEGD, and the general supervision of Drs. M. E. Hynes, Acting Chief, GEGD, and Michael J. O'Connor, Director, GL.

At the time of publication of this report, Director of ERDC was Dr. James $R$. Houston. Commander was COL James S. Weller, EN.

The contents of this report ane not to be used for advertising, publication. or promotional purposes. Citation of trade names does not constitute an official endorsement or approval of the use of such commencial products. 


\section{Conversion Factors, Non-SI to SI Units of Measurement}

Non-SI units of measurement used in this report can be converted to SI units as follows:

\begin{tabular}{|l|l|l|}
\hline Multiply & By & To Obtain \\
\hline Feet & 0.3048 & Meters \\
\hline Gamma & 1.0 & Nanotesla \\
\hline
\end{tabular}





\section{Introduction}

The objective of the Work unit "Innovative Geophysical Technologies for Enhanced Buried UXO Discrimination" is to develop advanced geophysical technologies to enhance the ability to discriminate buried UXO in a wide range of environmental and geophysical conditions. The geophysical methods under study include multi-component magnetic, gravimetric, and time domain electromagnetics. This report details the initial findings using multi-component magnetic sensors.

With the closing of numerous installations and increased environmental awareness, a primary thrust of the Army is the cleanup of unexploded ordnance (UXO) from military-owned land and transfer of this land to the civilian sector. Geophysical methods are commonly employed for locating UXO. Of these methods, magnetometers (total field and gradient) and "simple" time domain electromagnetic (TDEM) instruments are routinely used. Both types of instruments are excellent for the detection of potential UXO, which are usually comprised of both ferrous and non-ferrous metals. The ubiquity of the UXO metallic make-up and the nature of the geophysical instrument measurement makes it very difficult to discriminate potentially dangerous UXO from non-threatening exploded ordnance fragments and waste, cultural objects, and anomalous geologic sources. A large percentage of the cost (approximately 75\%) of UXO cleanup efforts is attributed to the detection and excavation of "false alarm" anomalies, i.e., anomalies caused by buried ordnance debris, other metallic objects, and naturally occurring soil features (USAEC 19 JPG reference). Therefore it does not suffice to just detect an anomaly, it is necessary to discriminate and, ultimately, identify UXO.

The term "simple" used above to describe the TDEM instruments refers to those instruments that measure only one or two time gates within the transient decay window. The consensus among many UXO practitioners is that the total magnetic field, magnetic gradient, and "simple" TDEM measurements do not provide sufficient information to adequately discriminate UXO from other anomalies. Multi-component magnetic data, multi-channel TDEM data, or multi-sensor data likely are needed to obtain a more accurate description of the anomaly orientation (azimuth and dip), size and depth to allow discrimination of UXO from non-UXO anomalies. This report concentrates on multi-component magnetic data, specifically three component magnetic data acquired using a Bartington Mag-03 sensor.

The majority of UXO detection work that utilizes magnetometers measures the total magnetic field or gradient. Those surveys that do use a multi-component magnetometer, such as the Schiebel DIMADS ${ }^{\mathrm{TM}}$, generally do not evaluate the individual component data but rather calculate the total magnetic field from the 
components and use it. Much research has been done in evaluating the total magnetic field signature over UXO (e. g. Altshuler 1996; Barrow et al. 1996; Barrow et al. 1997; Barrow and Nelson 2000; Hollyer et al. 1997). Early work stressed the need for data coverage on the order of the size of the smallest ordnance item expected to be detected. These results were the impetus for designing multiarray sensor configurations (e.g. STOWS, MTADS). Even with the improvement in data coverage, the discrimination of UXO from ordnance waste and other man-made and geologic sources has lagged detection capabilities. The series of UXO Technology Demonstrations at Jefferson Proving Ground (USAEC 1994, 1995, 1996, 1997; Altshuler et al. 1995) emphasize this issue. Recent advances in UXO discrimination primarily have been achieved through computer analysis of total magnetic field data alone (modeling: Altshuler 1996; Barrow 2000; Barrow and Nelson 2000; Barrow et al. 1997; Butler et al. 1998; McFee and Das 1990; neural network analysis: Grimm 2000; Hart 2000; Millhouse 2000; image processing: Millhouse 2000) or through joint analysis with electromagnetic induction data (Collins 2000; Grimm 2000; Hart 2000; Lavely and Grimm 1997). The present work takes a different approach through the study of three-component magnetic data. Model data are generated and compared to field data collected under controlled field conditions. The data obtained for the three components are analyzed to determine if the additional information provided by the components aids in the discrimination of buried ordnance. 


\section{Theoretical Magnetic Models}

The forward magnetic modeling program MAGMOD was used to generate the response of a 105-mm projectile. The features and capabilities of MAGMOD are described in Butler et al. (1998) and Butler et al. (2000). MAGMOD is based on the theoretical development by McFee and Das (1990) and uses (1) a prolate spheroid and (2) a multipole expansion solution for the induced magnetic field external to the spheroid to approximate the shape of a projectile. The multipole expansion includes the dipole and octupole terms, having no monopole term and the quadrapole term is zero due to symmetry of the spheroid. Since the octupole term falls off at a rate of $1 / r^{5}$, the effect of higher order terms is negligible. Input to the program includes: the earth's field strength, inclination and declination; spheroid length, diameter, azimuth and dip; $x, y$ coordinates and depth to the spheroid center; relative magnetic permeability of model; sensor height and grid dimensions.

Figure 1 shows the model total magnetic field anomaly generated for a $105-\mathrm{mm}$ projectile as the azimuth is varied from $0^{\circ}$ to $90^{\circ}$ (constant dip) (a) and when the dip is varied from $0^{\circ}$ to $90^{\circ}$ (constant azimuth) (b). A geomagnetic field having a declination of $0^{\circ}$ with an inclination of $65^{\circ}$ was used in constructing the models. Distance between the sensor and center of the spheroid is $50 \mathrm{~cm}$. The data were generated over a $5 \mathrm{~m} \times 5 \mathrm{~m}$ grid using a $12.5 \mathrm{~cm}$ spacing. The image plots use the same shading scale. The profile plots below each image plot represent the northsouth profile across the center of the image plot. The $\mathrm{x}$ and $\mathrm{y}$ axes of the profile plots are to the same scale. As both the azimuth and dip increase toward $90^{\circ}$, the anomaly structure changes and approaches that of a monopole. Also note in Figure la that the magnetization vector (direction of dipole) lags that of the azimuth (Altshuler 1996). For a length to diameter ratio of 4, which is the aspect ratio of a 105-mm projectile, the magnetization vector begins to lag the azimuth at azimuths greater than about $5^{\circ}$. A maximum lag of $22^{\circ}$ occurs when the angle between the long axis of the projectile and the geomagnetic field is $68^{\circ}$.

A uniformly magnetized sphere (simple induced dipole) is the simplest model for approximating the anomalous response of a UXO. Figure 2 depicts plots of a spherical model fit to the profiles in Figure 1. A sphere having a diameter of $15 \mathrm{~cm}$ was arbitrarily chosen and does not represent an equivalent volume to the $105-\mathrm{mm}$ projectile. The only parameter to vary using a spherical model is depth (z), yet fairly good fits to the spheroid models are obtained, especially when the azimuth (with dip $=0^{\circ}$ ) (a) and dip (with azimuth $=0^{\circ}$ ) (b) are $90^{\circ}$. However, the spherical model does not provide any information on the azimuth, dip or shape of the buried object. More sophisticated models, such as a full-field solution (Stratton 1941; 
Altshuler 1996), or a dipole or multipole expansion solution for a spheroid, or multi-component data are needed to achieve discrimination and identification of UXO.

The total magnetic field $\overrightarrow{\mathrm{Ht}}$ can be described by its vector components $\overrightarrow{\mathrm{Hx}}$, $\overrightarrow{\mathrm{Hy}}, \overrightarrow{\mathrm{Hz}}$ and its orientation with respect to the horizontal and vertical planes. By

convention, $\overrightarrow{\mathrm{Hx}}$ points in the direction of true north (TN). Referring to the diagram below, the declination $\mathrm{D}$ is the angle measured in the horizontal plane between

$\overrightarrow{\mathrm{Hx}}$ and magnetic north $(\mathrm{MN})$, and the inclination is the angle the total magnetic field vector makes with the horizontal plane.

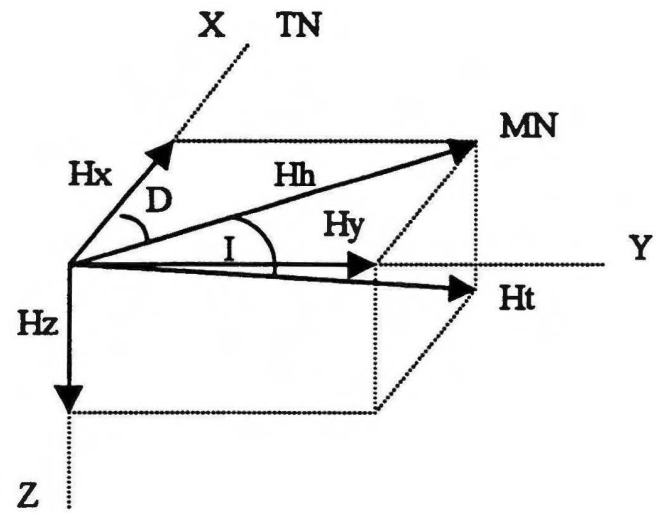

$$
\begin{aligned}
& H x=H h \cos D \\
& H y=H h \sin D \\
& H z=H t \sin I \\
& H h=H t \cos I
\end{aligned}
$$

Magnetic component space plots for the 105-mm spheroid discussed above are plotted in Figure 3. The component data correspond to the north-south profile acquired across the center of the image plots in Figure 1, where each point on the plots in Figure 3 correspond to the $(\mathrm{Hx}, \mathrm{Hz})$ or $(\mathrm{Hx}, \mathrm{Hy})$ values for a point on the profile lines. Figure $3 \mathrm{a}$ is for the case dip $=0^{\circ}$ and azimuth varies $0^{\circ}$ to $90^{\circ}$. The left plot represents the vertical component $\mathrm{Hz}$ plotted against the horizontal component $\mathrm{Hx}$, whereas the right plot is the horizontal component $\mathrm{Hy}$ versus $\mathrm{Hx}$. The directional components are oriented based on a right-hand system with $\mathrm{z}$ positive downward ( $x$ north, $y$ east). The heart-shaped $\mathrm{Hz}-\mathrm{Hx}$ curves are not symmetrical. At an azimuth of $0^{\circ}$ the curve lays horizontal ("heart" on its side) and as the azimuth of the projectile increases, the curve rotates toward a vertical position. The curves in the horizontal component plot $\mathrm{Hy}-\mathrm{Hx}$ are quite different depending on azimuth. Due in part to symmetry of the spheroid and the fact that the geomagnetic field is directed in the $\mathrm{x}$ (north) direction, no variation in the $y$-component is observed at an azimuth of $0^{\circ}$ and the curve is a horizontal line. In addition to these two factors, when the spheroid is rotated from the direction of the geomagnetic field, the magnetization vector follows but lags the long axis of the spheroid up to a maximum angle, at which point the direction of magnetization begins to move back toward the direction of the geomagnetic field. At an azimuth of $90^{\circ}$ the magnetization vector returns parallel to the geomagnetic field (Altshuler 1996); the horizontal line for a $90^{\circ}$ azimuth in the Hy-Hx plot reflects this phenomenon. As the azimuth of the spheroid increases from $0^{\circ}$, a magnetic influence is now present in both the $x$ - and $y$-components and a "tornado-shaped" curve forms that rotates toward vertical. When the azimuth is held constant and the 
dip of the projectile is varied, $\mathrm{Hz}-\mathrm{Hx}$ plots similar to those when the azimuth was varied are obtained (Figure 3b). The heart curve is relatively horizontal at a dip of $0^{\circ}$ and rotates to vertical as the dip of the projectile increases to $90^{\circ}$. The $\mathrm{Hy}-\mathrm{Hx}$ curves are a horizontal line for all dips, indicating a zero y-component which is expected for an azimuth of $0^{\circ}$ and a north oriented geomagnetic field. 


\section{Field Acquisition and Data Review}

This section describes how the field data were obtained and presents the results of the three magnetic components measured, both as profile plots and image plots.

\section{Data Acquisition}

Three component magnetic data were acquired under controlled field conditions. A Bartington Mag-03MS low noise sensor having a measuring range of \pm 100 microtesla was used. The sensor has a noise error of 6 picotesla $\mathrm{rms} / \sqrt{\mathrm{Hz}}$ and an orthogonality error of $\pm 0.1 \%$. The Mag-03 is a fluxgate sensor that measures three components of the magnetic field, two horizontal and one vertical. The components are oriented in a right hand system with the vertical positive downward. The survey grid measured 4 meters east-west and 5 meters north-south. Data were collected at a height of $25 \mathrm{~cm}$ above the ground surface with a horizontal spatial increment of $25 \mathrm{~cm}$. Figure $4 \mathrm{a}$ shows the measurement stand and $4 \mathrm{~b}$ the sensor holder. A bubble level was mounted on the sensor holder and a wood wedge was used to level the sensor. No metal was used in the construction of the measurement stand nor the sensor holder. Data were collected over a $105-\mathrm{mm}$ projectile (length $42 \mathrm{~cm}$, diameter $10.5 \mathrm{~cm}$ ) in a horizontal position ( $\mathrm{dip}=0^{\circ}$ ) and for north-south (nose pointing north) and east-west (nose pointing east) orientations. The projectile was located in the center of the grid and buried at a depth of $5.25 \mathrm{~cm}$, measured to the center of the projectile; the top surface of the $105-\mathrm{mm}$ was at ground surface. A base station also utilizing a Mag-03MS sensor was used to correct for diurnal variations. The data acquisition module for the Mag- 03 sensor allows input from two channels, therefore a base station reading was acquired each time a measurement on the survey grid was collected.

\section{Data Presentation}

The component data plots $\mathrm{Hz}-\mathrm{Hx}$ and $\mathrm{Hy}-\mathrm{Hx}$ for both azimuthal orientations are presented in Figure 5. The data are from the north-south profile acquired along the centerline of the grid. The model curves generated using MAGMOD for a 105$\mathrm{mm}$ projectile and using the local earth magnetic field parameters (except for the declination which was fixed at zero) are also plotted for comparison. Figure 5a shows the component plots for an azimuth of $0^{\circ}$. The $\mathrm{Hz}-\mathrm{Hx}$ curves are similar in 
shape for both the model and field data, although the field data has a greater range in magnitude. The model curve exhibits an inner loop that is caused by the influence of the octupole term. The octupole term has its greatest influence when the distance between the object and magnetic sensor is less than the length of the object. In this case, length of the 105-mm projectile is $42 \mathrm{~cm}$ and "sensor" to center of spheroid distance is $30.25 \mathrm{~cm}$. The model data are generated at twice the density of the field data and it is not certain that the influence of the octupole term would be observed if the field data were collected at a greater density. The Hy-Hx component field curve is elongated in the $\mathrm{x}$-direction as predicted by the model, however it does exhibit some noise in the data. In Figure $5 \mathrm{~b}$ it can be seen that the $\mathrm{Hz}-\mathrm{Hx}$ model curve approximates the field curve quite well when the projectile has a $90^{\circ}$ azimuth orientation. Note there is no visible presence of the octupole term in the model curve, as was seen when the projectile was oriented north $\left(\mathrm{Az}=0^{\circ}\right)$. The $\mathrm{Hy}-\mathrm{Hx}$ component plot is quite interesting. The model curve indicates there should be no variation in the y-component, resulting in a horizontal line, yet the field curve shows variation in the y-component about three times greater than that of the $x$-component. Some of this variation could be due to the asymmetry of the projectile. However, such a large variation suggests that the $105-\mathrm{mm}$ projectile, which has not been fired, possesses remanent magnetization. A simple test to check for remanent magnetization was performed. Two north-south profiles were acquired over the projectile, one with the $105-\mathrm{mm}$ oriented pointing north and the other south (Figure 6). The two profiles should be similar if no remanent magnetization is present. These profiles are radically different, indicating a strong remanent magnetization component.

An example of no remanent magnetization present is shown in Figure 7 for a non-ordnance steel projectile. The projectile has a length of $36 \mathrm{~cm}$, diameter of $5 \mathrm{~cm}$, and was filled with sand prior to firing into concrete. Four profiles with the projectile pointing north, south, east and west are plotted. The profile acquired when the projectile is pointing south should be similar to the north-pointing profile, and the east and west profiles should be similar. As can be seen, the two northsouth profiles are similar in shape and likewise the two east-west profiles are similar. The impact of the projectile with the concrete has realigned the magnetic dipoles, removing the presence of any remanent magnetization. To determine the remanent magnetization vector, it is not sufficient to measure a single profile over the projectile. Barrow et al. (2000) suggest acquiring measurements over a grid, with the projectile located at the center and at different orientations, and fitting a dipole model to the data. Determining the strength and direction of the remanent magnetization is not within the scope of this report.

It is also instructional to look at image plots of the individual magnetic components. Figure 8 shows plots of both model and field data for the total magnetic field $\mathrm{Ht}$ and three components (vertical $\mathrm{Hz}$, horizontal $\mathrm{Hx}, \mathrm{Hy}$ ). The model plots were generated using the known field parameters and 105-mm dimensions. In Figures $8 \mathrm{a}$ and $8 \mathrm{~b}$, the upper plots are for an azimuth of $0^{\circ}$, and the lower plots for an azimuth of $90^{\circ}$ (dip $0^{\circ}$ in both cases). For a given component, the plots for $\mathrm{Az}=0^{\circ}$ and $\mathrm{Az}=90^{\circ}$ use the same shading scale, although the scales between components and the model and field plots differ. This gray scale uses black to indicate magnetic lows and white for magnetic highs. The model plots (Figure 8a) have a similar structure for both azimuthal orientations of the spheroid, 
although the magnitude of the data is less for an azimuth of $90^{\circ}$. The similarity is attributed to the symmetry of the spheroid, having an approximately north pointing geomagnetic field (actual declination $1^{\circ}$ ), and lag between the magnetization vector and the projectile azimuth. The same sensor-projectile separation was used to generate these data as was used to acquire the field data. The small separation results in a dual (or double) dipole observed in the $\mathrm{Hx}$ (north component) plot for a $0^{\circ}$ azimuth. The two dipoles are attributed to the proximity of the sensor to the projectile and its ability to differentiate both ends of the projectile. At a greater separation the contours would appear as a single dipole. When the projectile is oriented at $90^{\circ}$, i.e. long axis of the projectile is perpendicular to the survey direction, it is perceived as a single dipolar signature. In the Hy (east) component plots a dipolar anomaly is sensed on both the west and east sides of the projectile, separated by a zero magnitude contour along the centerline. When the sensor is on the west side of the projectile the magnetic influence of the projectile is in the positive $y$-direction, thus giving a positive-negative dipole, whereas when the sensor is east of the projectile the magnetic influence is in the negative $y$-direction, resulting in a negative-positive dipole.

The component images for the field data are plotted in Figure $8 \mathrm{~b}$. For an azimuth of $0^{\circ}$, the field plots are similar to those predicted by the model, although the range of magnitude is greater in the field data. Without any knowledge on the subsurface placement of the projectile and assuming no remanent magnetization, some general statements can be inferred from the data. The classic dipolar response in the total magnetic field plot suggests the projectile is oriented at roughly $0^{\circ}$ or $90^{\circ}$ azimuth. The dual dipole observed in the $\mathrm{Hx}$ component indicates the projectile length is at least as great as the sensor-projectile distance, concluding the projectile is relatively shallow and of moderate length or it is a larger projectile at greater depth. Inspection of north-south and east-west profiles over the object may aid in determining whether the projectile is oriented at an azimuth of $0^{\circ}$ or $90^{\circ}$. Model profiles extracted from the centerlines of the total magnetic field (Ht) grids in Figure 8 are plotted in Figure 9 along with the field curves. Figure 9a compares the model profiles for an azimuth of $0^{\circ}$ to the field profiles, and those in Figure $9 \mathrm{~b}$ are for a $90^{\circ}$ azimuth. As expected, the model curves for an azimuth of $0^{\circ}$ provide the better fit. An attempt to improve the fit for the model $\mathrm{Az}=90^{\circ}$ by decreasing the projectile depth would increase the magnitude of the total magnetic field, resulting in a better fit to the north-south profile and worse fit for the east-west profile. Thus, the general conclusion is the projectile is oriented with its long axis parallel to the geomagnetic field, $A z=0^{\circ}$. The above discussion is based on the assumption that the projectile has no permanent magnetization. In this case, the 105-mm under study has not been fired and is known to have a significant remanent magnetization component. However, a detailed study by Barrow and Nelson (2000) involving the collection and analysis of spatially dense magnetometer data and ground truth of many of the anomalies, revealed that ordnance intact after impact showed little or no remanent magnetization, whereas ordnance debris and non-ordnance items were relatively magnetic. Therefore, the assumption that the measured magnetic field over buried UXO is primarily in response to the induced magnetization is valid.

The data acquired over the 105-mm projectile when it is oriented at an azimuth of $90^{\circ}$ (Figure $8 \mathrm{~b}$ ) is quite different than the model (Figure 8a), strongly suggesting the presence of remanent magnetization. The aspect ratio, length to diameter, of many UXO is in the range 3 to 6. Altshuler (1996) shows that in this range the 
maximum angle achieved between the long axis of the projectile and the geomagnetic field is $\mathbf{5 7}$ to $\mathbf{7 3}$ degrees, respectively, beyond which the magnetization vector moves back towards the direction of the geomagnetic field. The horizontally oriented dipole observed in the total magnetic field (Ht) plot clearly indicates a strong remanent magnetization component. A prolate spheroid will become magnetized more easily along its long axis than its semiminor axis (Altshuler 1996). Thus, it can be assumed that any remanent magnetization present is likely in the direction of the semimajor axis. Based on the total magnetic field image plot, it can be concluded that remanent magnetization is present and that the object is buried in an east-west direction. Note that the behavior of the $\mathrm{x}$ - and $\mathrm{y}$-component is opposite that for an azimuth of $0^{\circ}$, another indication that the orientation is east-west. Recall in Figures 5a and 9a that the range in magnitude of the field data is greater than that predicted by the model. A remanent magnetization component aligned with the long axis of the projectile reinforces the induced magnetic field when the projectile is directed north. Without knowing the actual orientation of the $105-\mathrm{mm}$ projectile, one can state that the object causing the anomaly does possess remanent magnetization but it is questionable whether the degree of remanent magnetization can be ascertained to allow determination of the true projectile position. If no remanent magnetization is assumed, the north-south model profile for an azimuth of $90^{\circ}$ provides a relatively good fit to the field data, however there is no similarity between the model and field east-west profiles (Figure 10). Based on the findings of Barrow and Nelson (2000) that fired UXO exhibit little or no remanent magnetization, it may be concluded that the anomaly caused by this projectile is not a UXO and poses no threat. Although this conclusion would be correct since this particular 105-mm projectile is inert, the discovery of an intact projectile in the subsurface on formerly owned military property tends to alarm the individual that unearthed the projectile, local governments, and the general public. Thus, there is an urgent and justifiable need to delineate, differentiate, and identify anomaly sources.

\section{Sensor Levelness}

A primary concern of using three component magnetic sensors is the feasibility of their use in a typical field environment. Accurate component measurements are dependent on proper orientation and levelness of the sensor. To check the effect of improper leveling of the sensor, controlled magnetic field measurements were collected along a 5m north-south profile line with no ordnance present using the measurement stand pictured in Figure 5. The stand has less than a $10^{\circ}$ incline from south to north over the $5 \mathrm{~m}$ distance. Even when the sensor was leveled using a bubble level mounted on the sensor holder, the sensor was not completely level. A comparison of average, minimum, and maximum angles calculated from accelerometer measurements along the survey grid during level and non-level states is given in Table 1. The accelerometer measurements acquired when the sensor was level are only from one line on the grid because there was little variation in the measurements. When the sensor was assumed to be level, the $x$ - and $y$-axis were still about $1.5^{\circ}$ off level. Removing the average tilt value when the sensor is level from the average non-level angle results in a compensated average tilt of $3.5^{\circ}$ for the $\mathrm{x}$-axis and $0.3^{\circ}$ for the $y$-axis. 


\begin{tabular}{|l|c|c|c|c|c|c|c|}
\hline \multicolumn{1}{|c|}{ Table 1. Tilt Angles Measured for Level and Non-Level Sensor } \\
\hline & \multicolumn{3}{|c|}{ Sensor Level ( ${ }^{\circ}$ tilt) } & \multicolumn{4}{c|}{ Sensor Not Level ( ${ }^{\circ}$ tilt) } \\
\cline { 2 - 8 } & Avg & Min & Max & Avg & Min & Max & Avg - Avg Level \\
\hline x-direction & 1.61 & 1.53 & 1.68 & 5.12 & 1.16 & 7.10 & 3.51 \\
\hline y-direction & 1.52 & 1.48 & 1.56 & 1.18 & -0.17 & 2.58 & 0.34 \\
\hline
\end{tabular}

The three magnetic field components were measured with the sensor holder both level and not level. These data and the calculated total magnetic field are presented in Figure 11. Variation in the individual components when the sensor is not level ranges from approximately 3 to 18 times that with it level. Table 2 gives the variation observed for each component under both level and non-level conditions. The large variation in the Hy component level data is likely attributed to the measurement stand having less stability in that direction. Calculation of the total magnetic field from the components tends to minimize the non-level effects, with the variation in the non-level data about three times greater than the level data. Further study is needed to determine if there is a relationship that can be exploited to mathematically compensate for a non-level sensor.

\begin{tabular}{|l|c|c|c|c|}
\hline \multirow{2}{*}{$\begin{array}{l}\text { Table 2. Variation in Measured Magnetic Field Components for a Level and Non-Level } \\
\text { Sensor }\end{array}$} & \multicolumn{4}{c|}{ Variation (nT) } \\
\cline { 2 - 5 } & $\mathrm{Hx}$ & $\mathrm{Hy}$ & $\mathrm{Hz}$ & $\mathrm{Ht}$ \\
\hline & 2580 & 2080 & 1215 & 46 \\
\hline Not Level & 140 & 718 & 77 & 16 \\
\hline Level & 18.4 & 2.9 & 15.8 & 2.9 \\
\hline Ratio & &
\end{tabular}




\section{Summary}

This initial study suggests that three-component magnetic data may provide valuable information that is not obtainable using conventional total field magnetometers. The additional information will aid in the discrimination and identification of UXO. As seen in the examples above, the vertical z-component tends to mimic the total field measurement, although the magnitude is less. The horizontal $x$ - and $y$-components provide information that is not discernable in the total field data, such as relative depth and size of the buried object. They also contribute in determining the azimuthal orientation and direction of remanent magnetization.

There are obstacles to overcome if three-component magnetic sensors are to be used in practical field situations. The sensors are highly sensitive to orientation and levelness. An improperly oriented and non-level sensor can cause a magnitude increase in the variation of the magnetic field measured. One possible solution is to design an instrument that would allow the sensor to "float" in order to self-level. Another solution is to study the feasibility of developing mathematical expressions to correct for deviations in sensor orientation and levelness.

The presence of remanent magnetization in an object affects all types of magnetometers: total field, gradient, and multi-component. If the findings of Barrows and Nelson (2000) can be applied to all UXO contaminated sites, then any anomaly detected that exhibits obvious remanent magnetization can be eliminated as a possible UXO. Further study is needed to determine if, in general, UXO lose their magnetic history on impact, and explosive waste acquires a shock magnetization when the projectile explodes. Anomalies that have a weaker remanent magnetization component, where it is not obviously present from looking at a plot of the field data, will adversely affect the ability to correctly determine the depth, azimuth and dip of an anomaly source. It is questionable whether the magnitude of the remanent magnetization can be determined and removed from the data, leaving only the induced magnetic portion. Three-component magnetometers do provide a greater chance of identifying and isolating the remanent magnetization because it is possible to see how the individual components are affected. More studies on remanent magnetization and its influence on UXO, ordnance waste, man-made objects, and geologic material are needed. 


\section{References}

Altshuler, T.W. (1996). "Shape and orientation effects on magnetic signature prediction for unexploded ordnance," Proceedings of the UO Forum '96. Williamsburg, VA, 282-291.

Altshuler, T.W., Andrews, A.M., Dugan, R.E., George, V., Mulqueen, M.P., and Sparrow, D.A. (1995). "Demonstrator performance at the unexploded ordnance technology demonstration at Jefferson Proving Ground (Phase I) and implications for UXO clearance," IDA Paper P-3114, Institute for Defense Analyses, Alexandria, VA.

Barrow, B. (2000). "Magnetization of exploded ordnance fragments." The UXO/Countermine Forum. Anaheim, CA.

Barrow, B. and Nelson, H.H. (2000). "Analysis of magnetic and EMI signatures from impacted, intact ordnance and exploded fragments," The UXO Countermine Forum. Anaheim, CA.

Barrow, B., Khadr, N., DiMarco, R, Nelson, H.H. (1996). "The combined use of magnetic and electromagnetic sensors for detection and characterization of UXO," Proceedings of the Symposium on Applications of Geophysics to Environmental and Engineering Problems. SAGEEP 96, Keystone, CO, 469. 477.

Barrow, B., DiMarco, R, Khadr, N., and Nelson, H. (1997). "Processing and analysis of UXO signatures measured with MTADS," Proceedings of the UXO Forum '97. Nashville, TN, 8-18.

Butler, D., Wolfe, Paul J., and Hansen, Richard O. (2000). "Analytical modeling of magnetic and gravity signatures of unexploded ordnance," Journal of Environmental and Engineering Geophysics, in press.

Butler, D.K., Cespedes, E.R., Cox, C.B. and Wolfe, P.J. (1998). "Multisensor methods for buried unexploded ordnance detection, discrimination, and identification," Technical Report SERDP-98-10, U. S. Army Engineer Waterways Experiment Station, Vicksburg, MS. 
Collins, L. (2000). "Physics-based signal processing and sensor fusion for improved UXO detection," The UXO Countermine Forum. Anaheim, CA.

Grimm, R.E. (2000). "UXO discrimination using MTADS: Joint EM/magnetic ellipsoid modeling and neural-network analysis," The UXO Countermine Forum. Anaheim, CA.

Hart, S.J. (2000). "Probabilistic neural networks for unexploded ordnance (UXO) classification using data fusion of magnetometry and EM physics-derived parameters," The UXO Countermine Forum. Anaheim, CA.

Hollyer, G, Racic, G, and Butler, D.K. (1997). "Enhancing geophysical data acquisition, processing and analysis for UXO detection, characterization, and discrimination," Proceedings of the UXO Forum '97. Nashville, TN, 183-194.

Lavely, E.M. and Grimm, R. (1997). "Toward joint inversion of magnetic and electromagnetic data for improved discrimination of UXO," Proceedings of the UXO Forum'97. Nashville, TN, 394-403.

McFee, J.E. and Das, Y. (1990). "A multipole expansion model for compact ferrous object detection," Proceedings of the ANTEM Symposium on Antenna Technology and Applied Electromagnetics. Manitoba, Canada, 633-638.

Sparrow, D.A., Andrews, A.M., and Dugan, R.E. (1995). "Evaluation of individual demonstrator performance at the unexploded advanced technology demonstration program at Jefferson Proving Ground (Phase 1)," SFIM-AEC-ETCR-95033, U.S. Army Environmental Center, Aberdeen Proving Ground, MD.

Stratton, J. (1941). Electromagnetic Theory. McGraw-Hill, New York, NY.

U. S. Army Environmental Center (USAEC). (1994). "Unexploded ordnance advanced technology demonstration program at Jefferson Proving Ground (Phase I)," Report No, SFIM-AEC-ET-CR-94120, Aberdeen Proving Ground, MD.

USAEC. (1995). "Evaluation of individual demonstrator performance at the unexploded ordnance advanced technology demonstration program at Jefferson proving Ground (Phase I)," Report No. SFIM-AEC-ET-CR-95033, Aberdeen Proving Ground, MD.

USAEC. (1996). "Unexploded ordnance advanced technology demonstration program at Jefferson Proving Ground (Phase II)," Report No, SFIM-AEC-ETCR-96170, Aberdeen Proving Ground, MD.

USAEC. (1997). "UXO technology demonstration program at Jefferson Proving Ground, Phase III," Report No, SFIM-AEC-ET-CR-97011, Aberdeen Proving Ground, MD. 
$105 \mathrm{~mm}$ - Model Data

Incl $=65$, Decl $=0$, Fo $=50000 \mathrm{nT}, \mathrm{z}=50 \mathrm{~cm}$

(a) $\operatorname{Dip}=0$

Total Magnetic Field

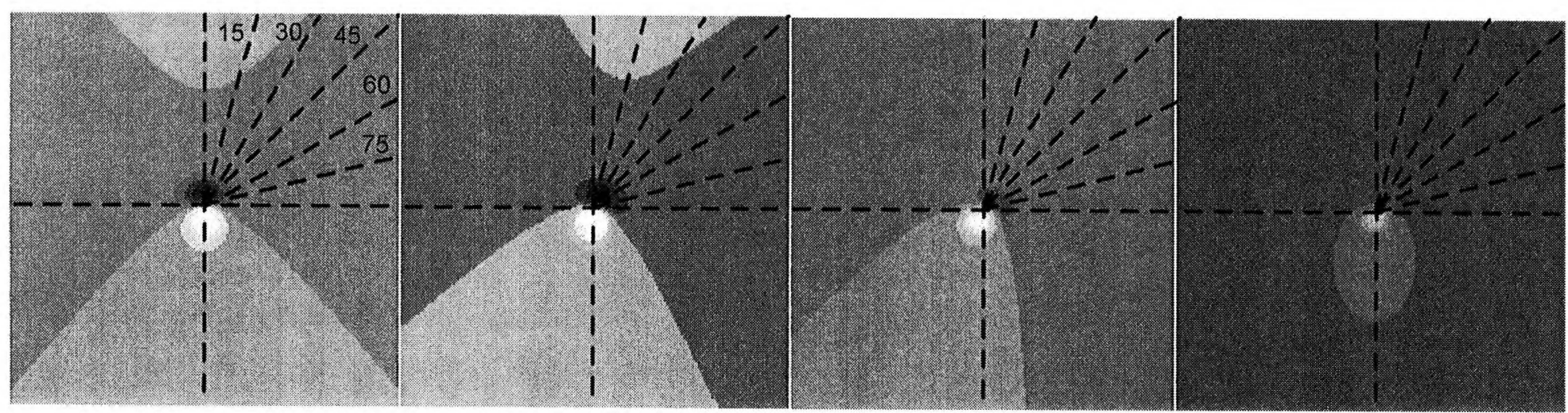

$A z=0$

$A z=30$

$A z=60$

$A z=90$
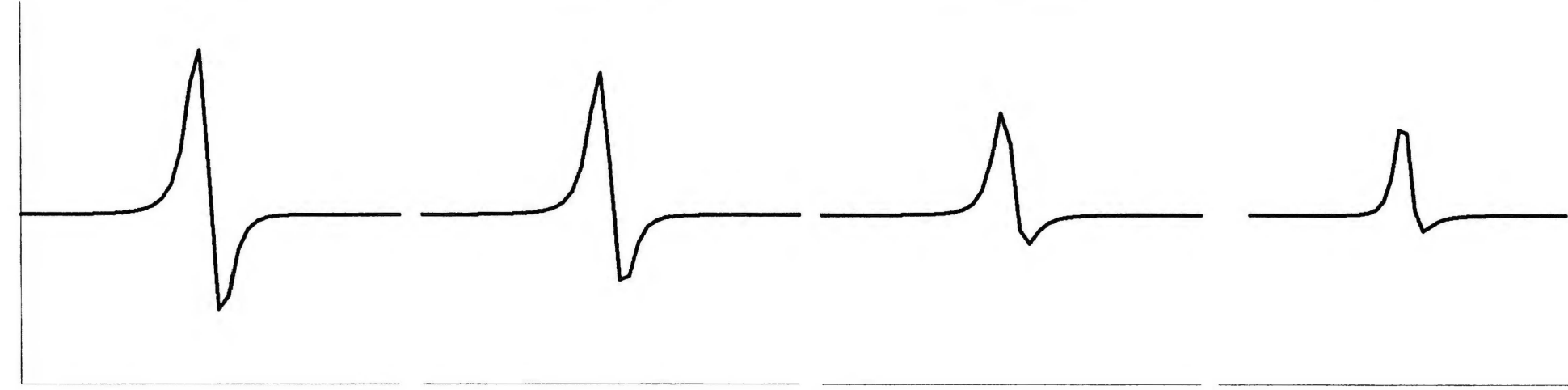

South to North Profiles Along Center Line

Figure 1. Total magnetic field model data generated for a $105-\mathrm{mm}$ spheroid (length $42 \mathrm{~cm}$, diameter $10.5 \mathrm{~cm}$ ). Parameters are: earth's field $50,000 \mathrm{nT}$, inclination 65 , declination 0 , distance between sensor and center of projectile $50 \mathrm{~cm}$, magnetic permeability 1000. (a) spheroid azimuth varies, spheroid dip $=0$. (b) spheroid dip varies, spheroid azimuth $=0$. 
(b) Azimuth $=0$
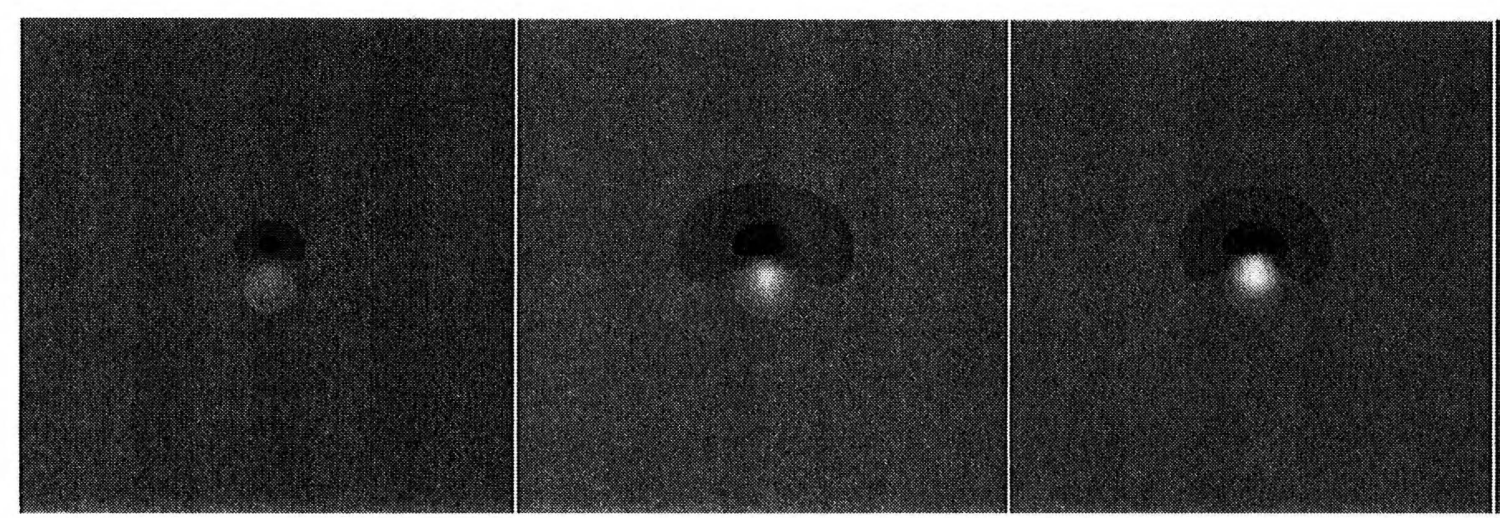

$$
\text { Dip }=0
$$

Dip $=\mathbf{3 0}$

Dip $=60$

$$
\text { Dip }=90
$$
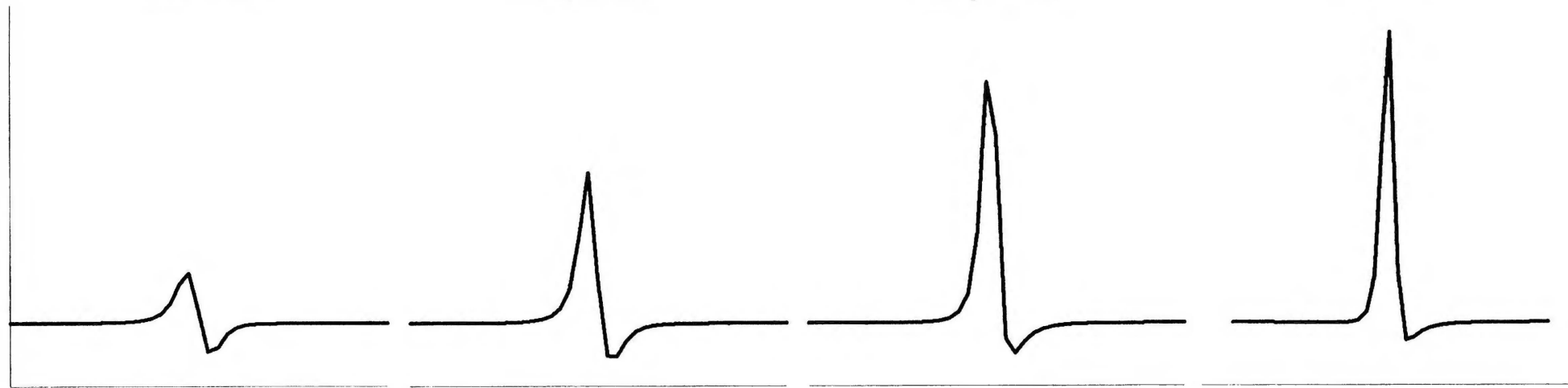

South to North Profiles Along Center Line

Figure 1. Concluded 
105-mm Model Data w/ Spherical Model Fit 105-mm: Dia $=10.5 \mathrm{~cm}, \mathrm{~L}=42 \mathrm{~cm} ;$ Sphere: $\mathrm{Dia}=15 \mathrm{~cm}$

(a) $\mathrm{Dip}=0$
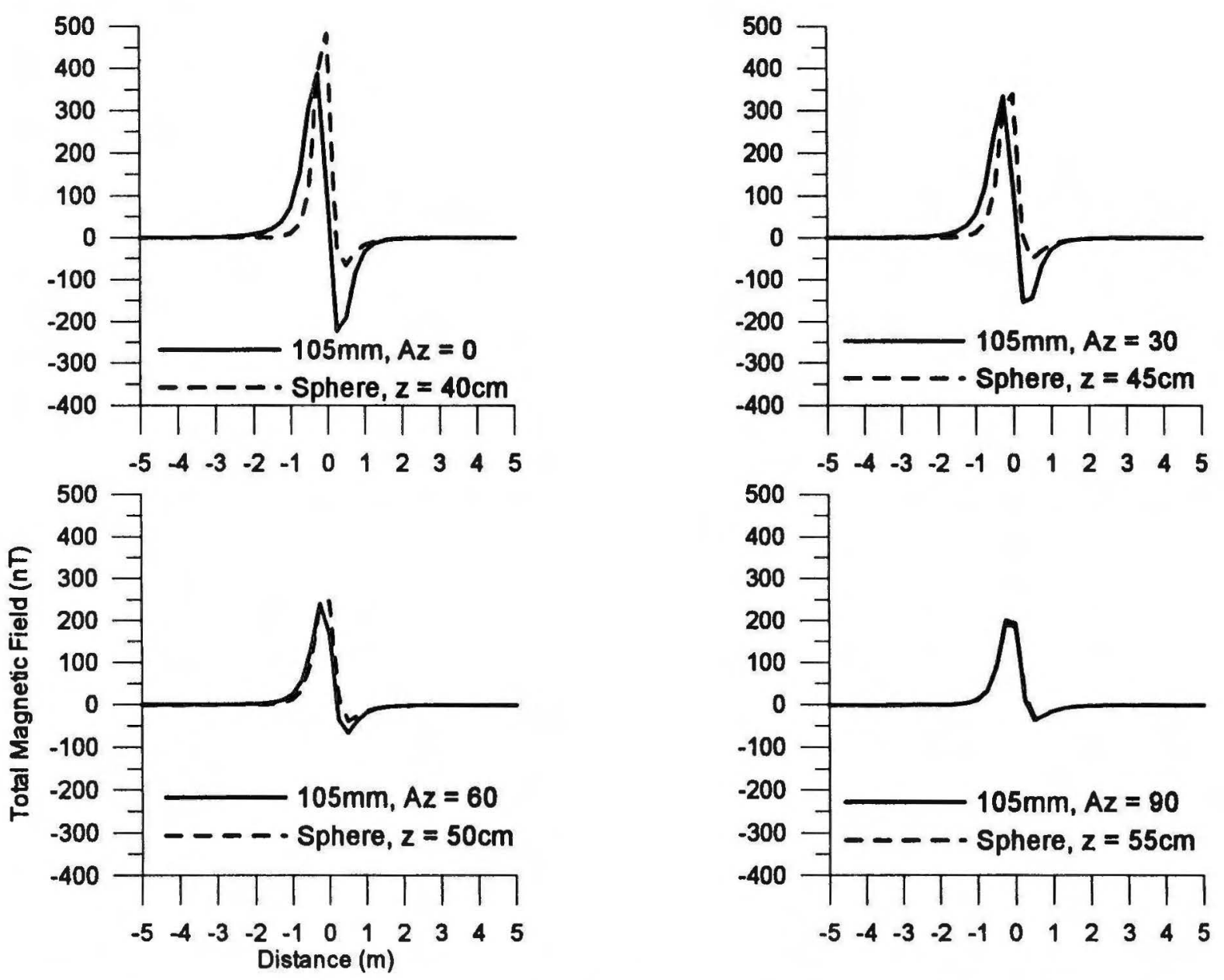

Figure 2. Spherical model fit to 105-mm spheroid model profiles in Figure 1. Sphere diameter $15 \mathrm{~cm}$. (a) spheroid azimuth varies, spheroid dip $=0$. (b) spheroid dip varies, spheroid azimuth $=0$. 
(b) Azimuth $=0$

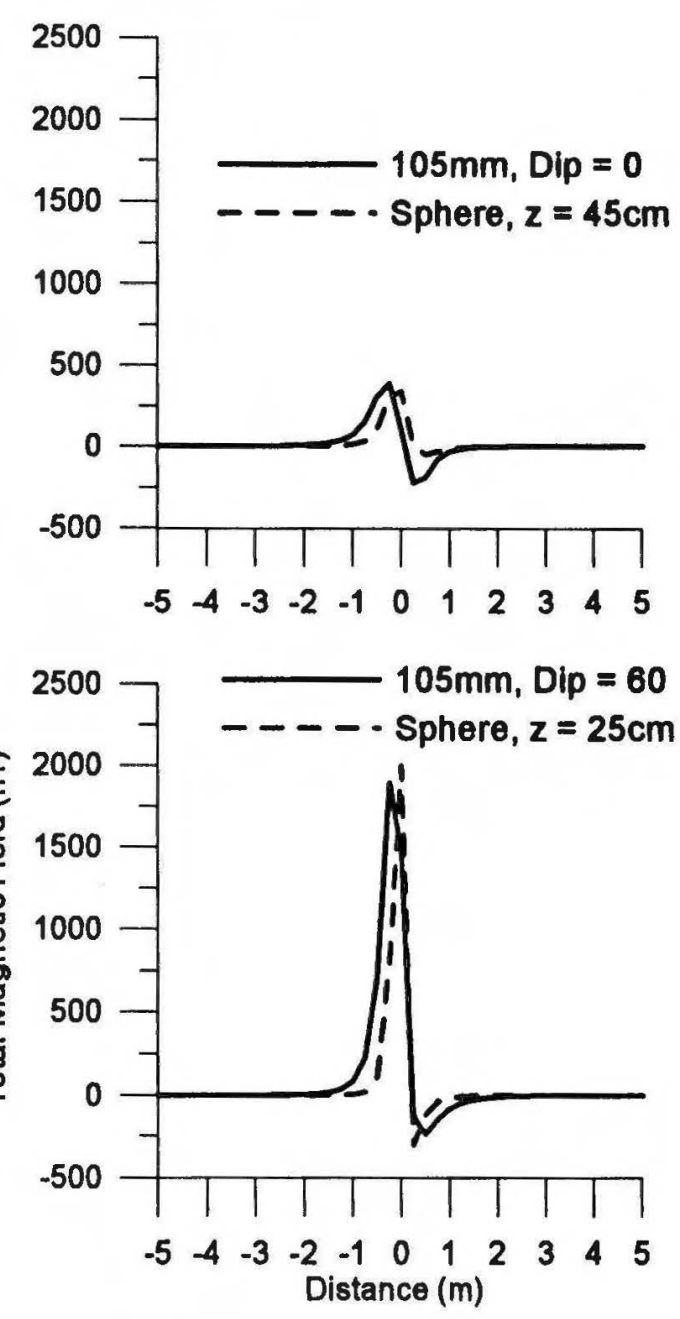

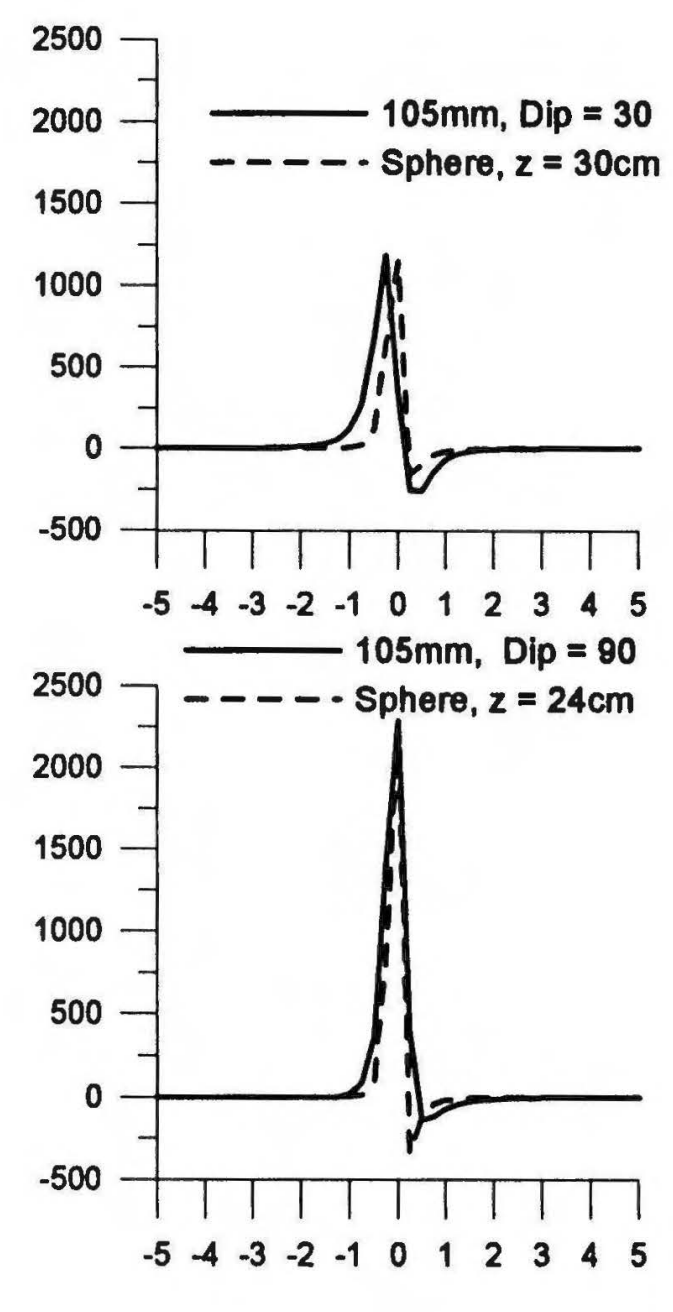

Figure 2. Concluded 
(a) Dip $=0$

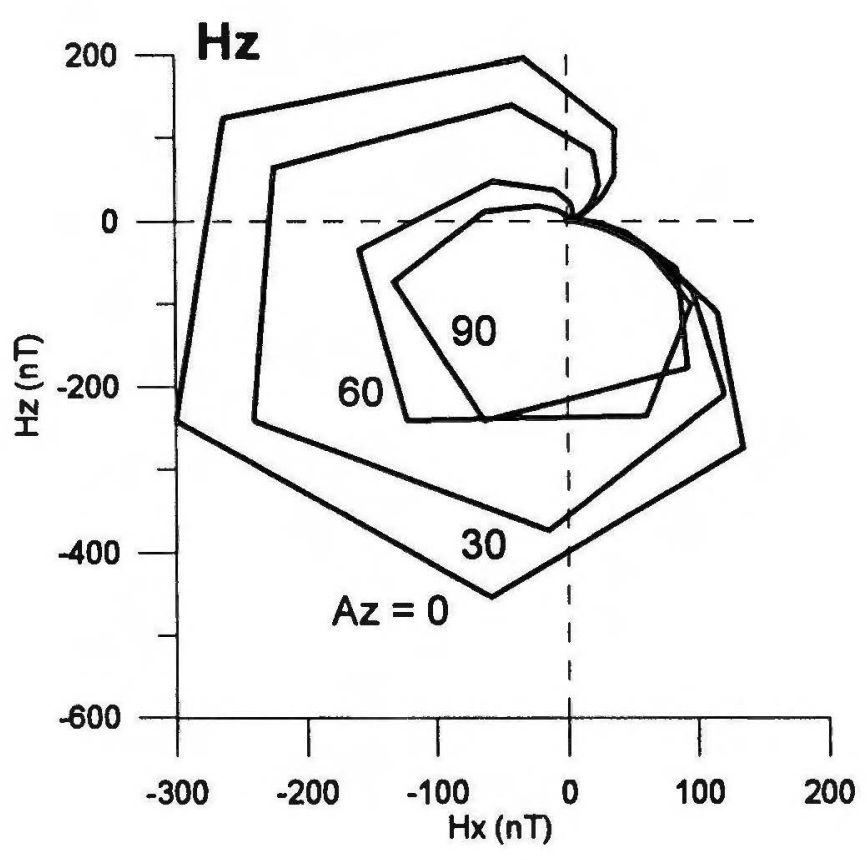

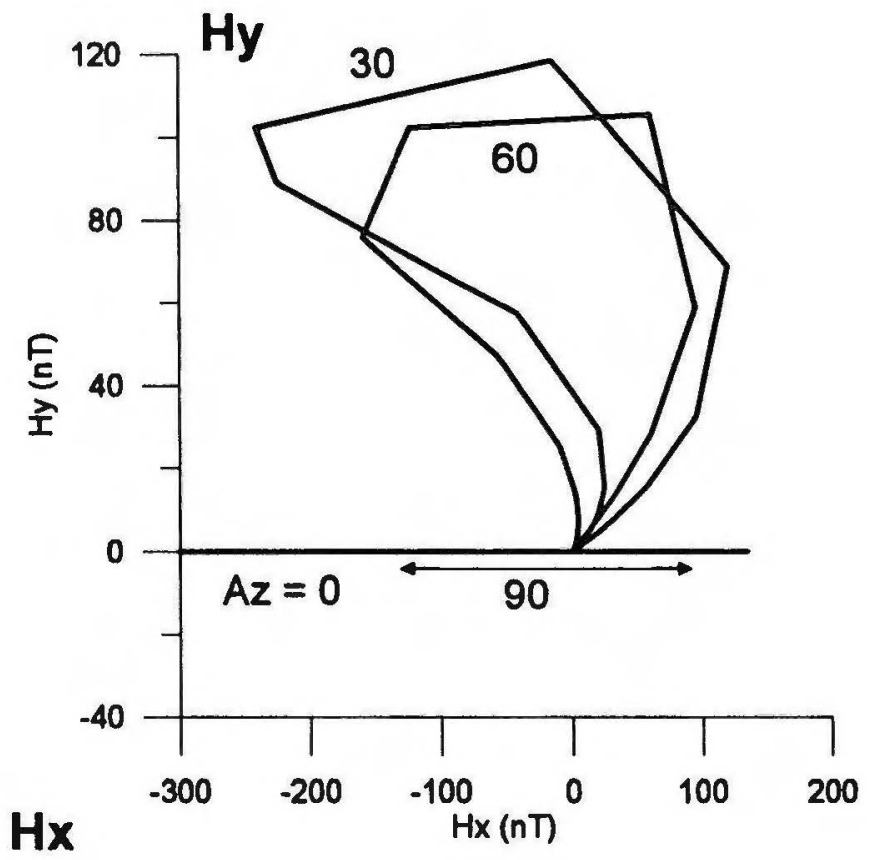

$\mathrm{Hx}$
Figure 3. Magnetic component plots for $105-\mathrm{mm}$ spheroid. (a) spheroid azimuth varies, 8 pheroid dip $=0$.

(b) spheroid dip varies, apheroid azimuth $=0$. 
(b) Azimuth $=0$
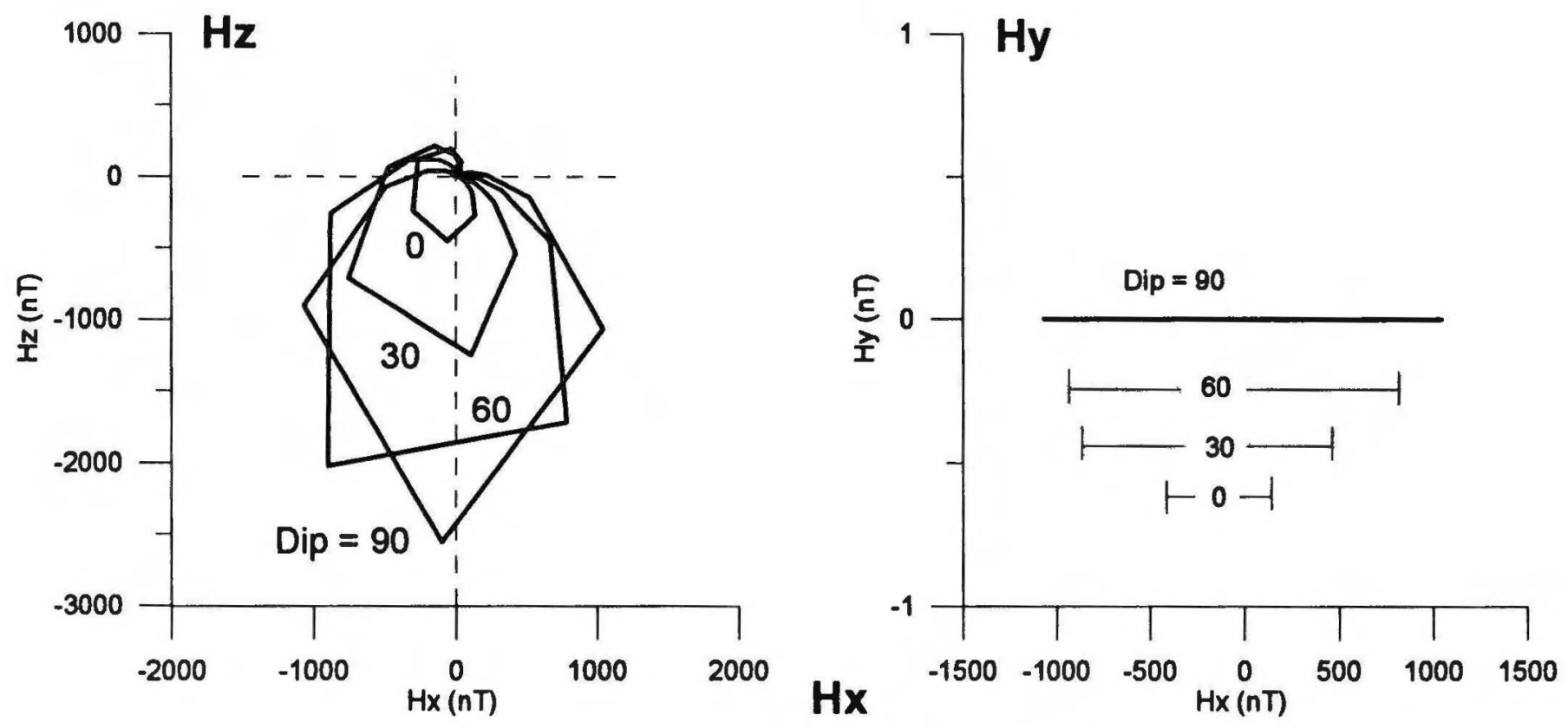

Figure 3. Concluded 
(a)

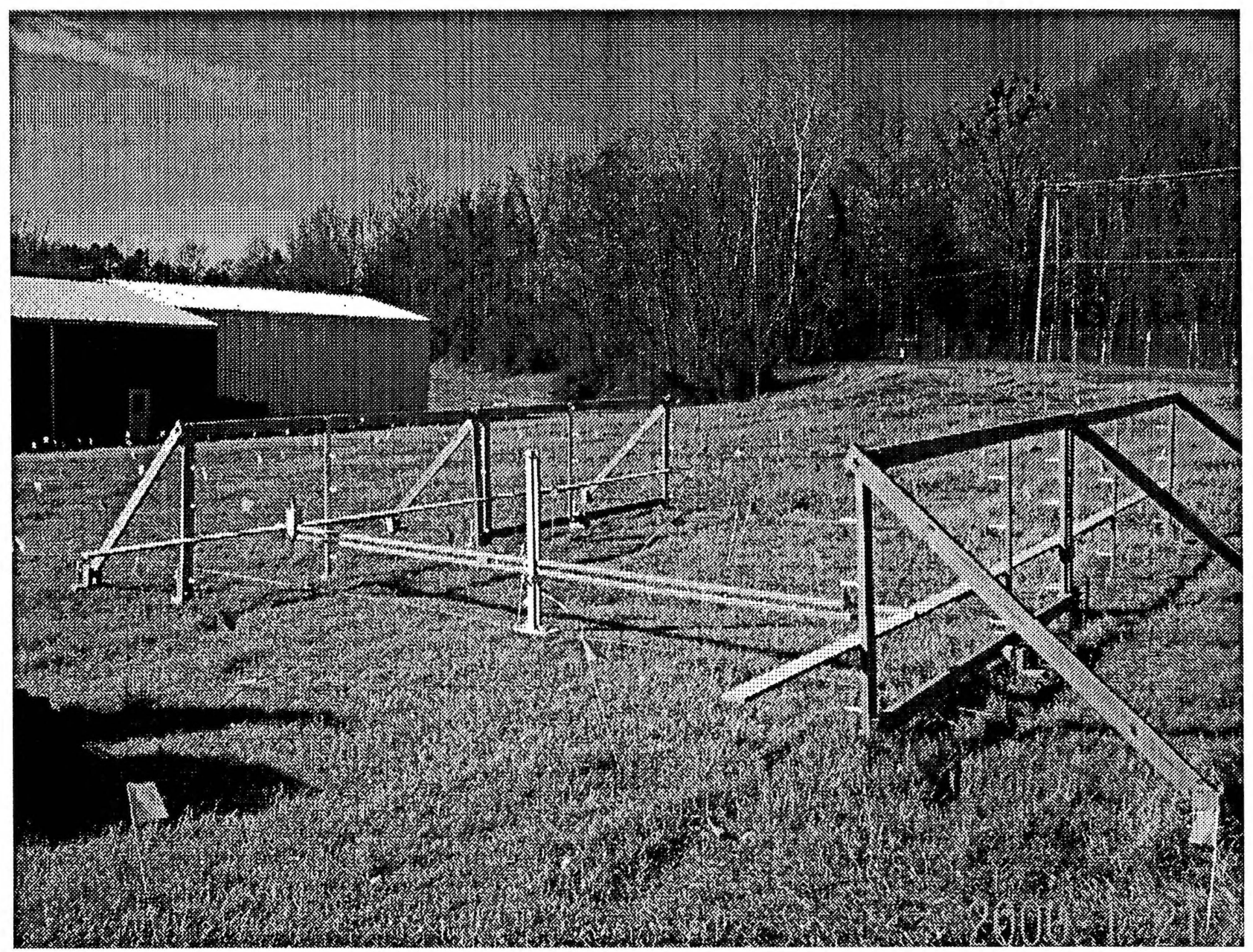

Figure 4. Apparatus used to collect three-component magnetic data in the field. (a) measurement stand. (b) magnetometer sensor in holder. 
(b)

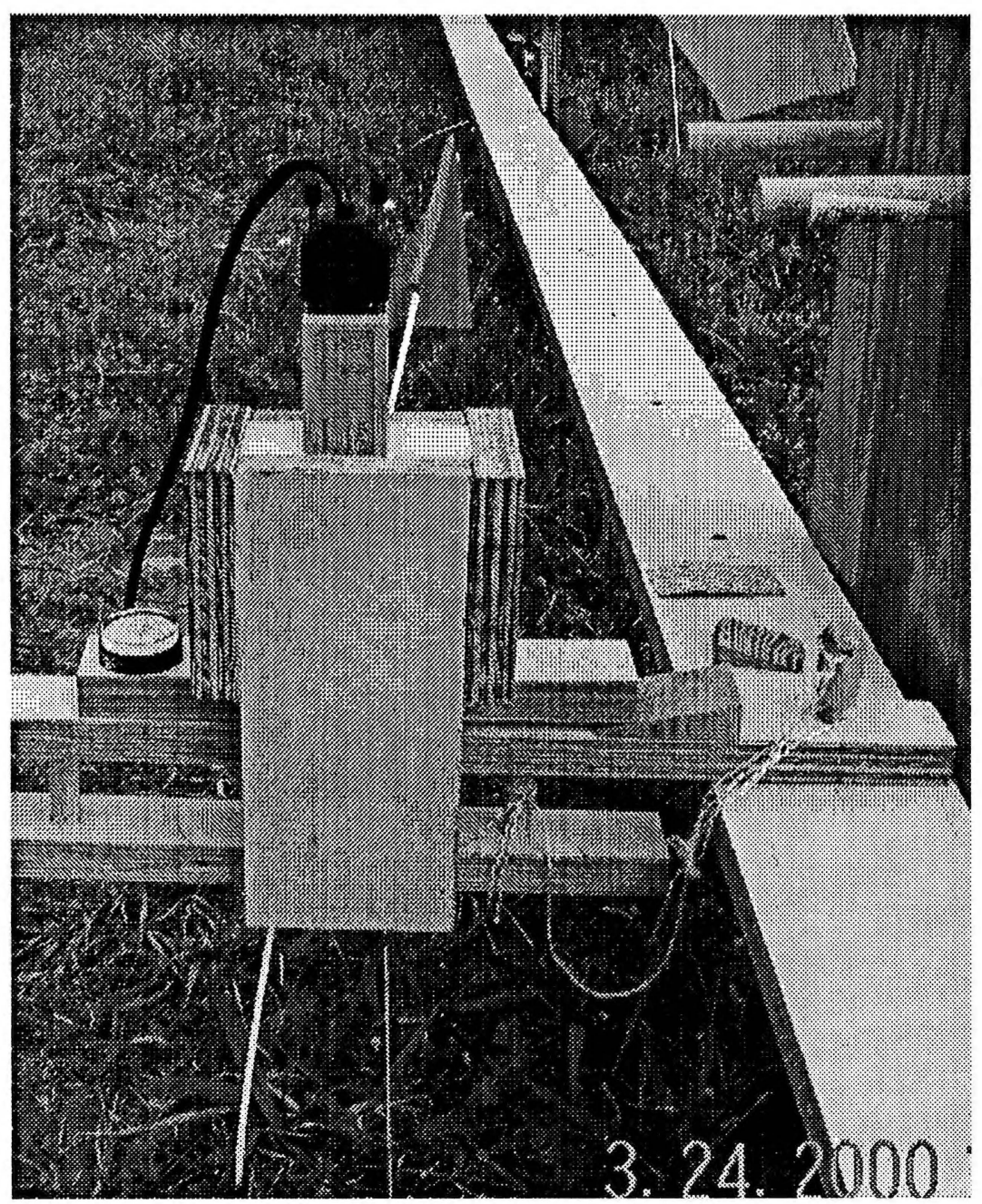

Figure 4. Concluded 


\section{5-mm Field Data w/ Spheroid Model Fit}

Incl $=62$, Decl $=0$, Dip $=0, z=30.25 \mathrm{~cm}$

(a) Azimuth $=0$
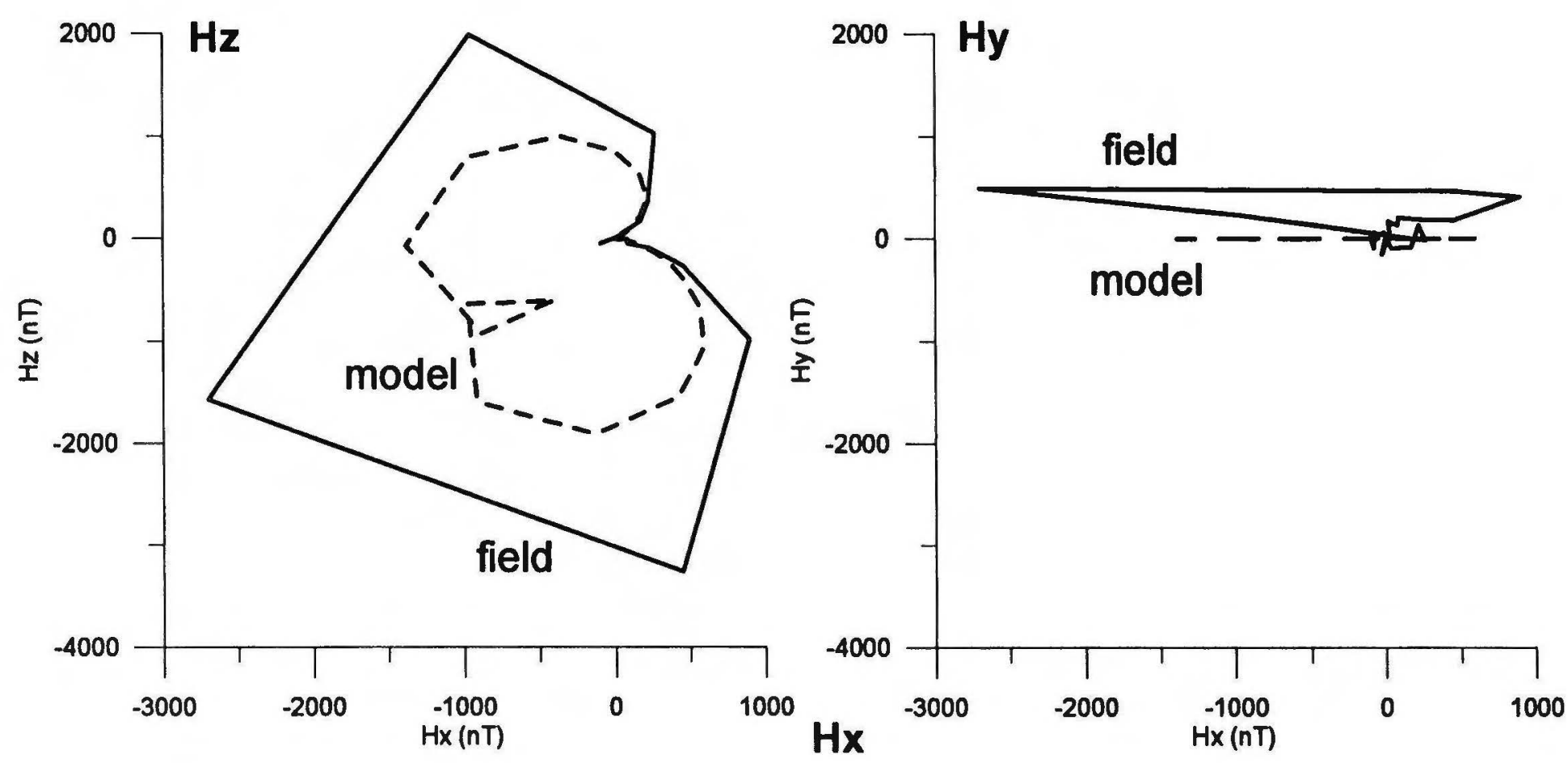

Figure 5. Magnetic component plots for 105-mm field data and spheroid model. Parameters are: earth's field 50,200nT, indination 62 , declination 0 , distance between sensor and center of projectile $30.25 \mathrm{~cm}$, magnetic permeability 1000 . (a) projectile azimuth $=0$, dip $=0$. (b) projectile azimuth $=90$, dip $=0$. 


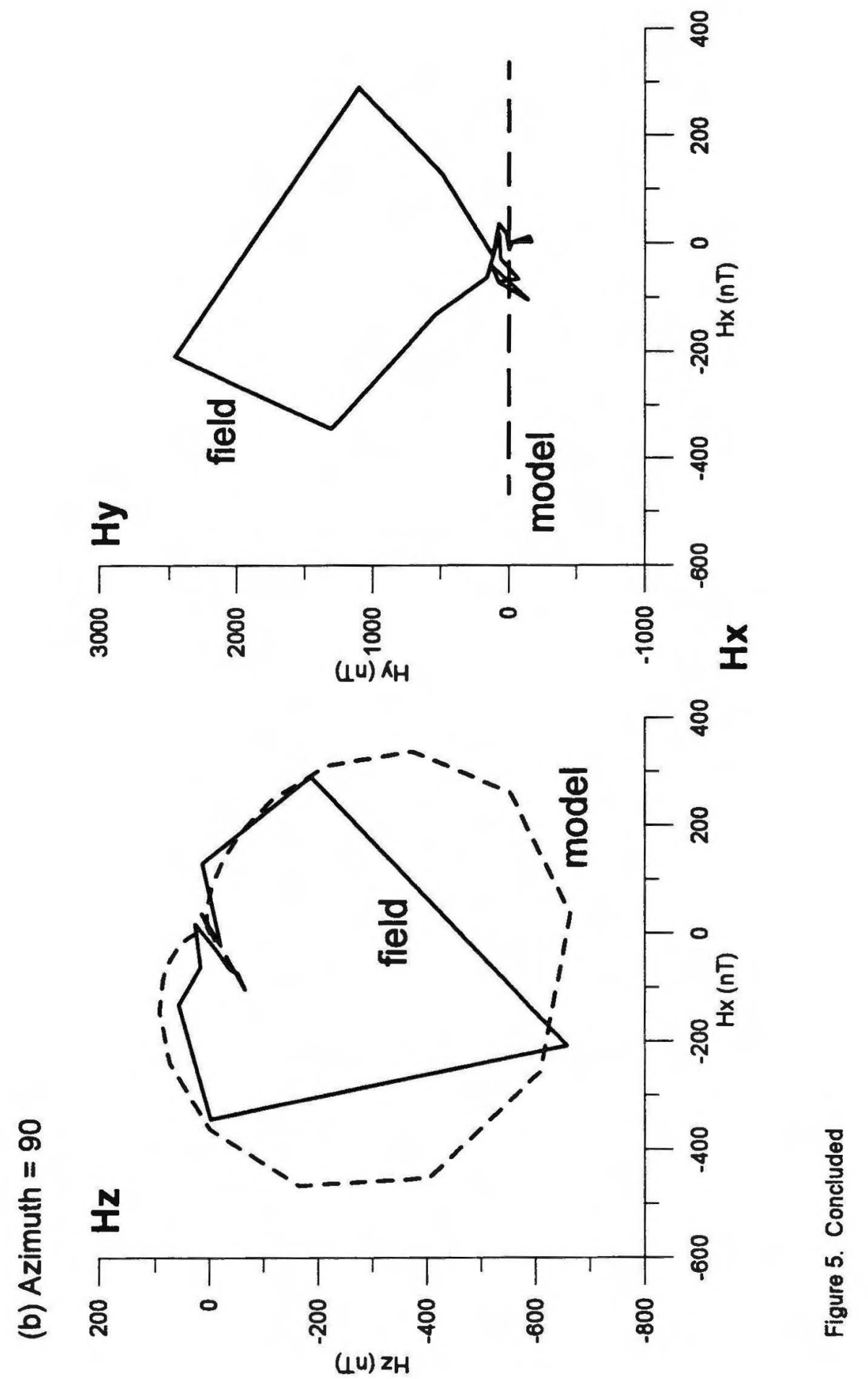




\section{5-mm Projectile}

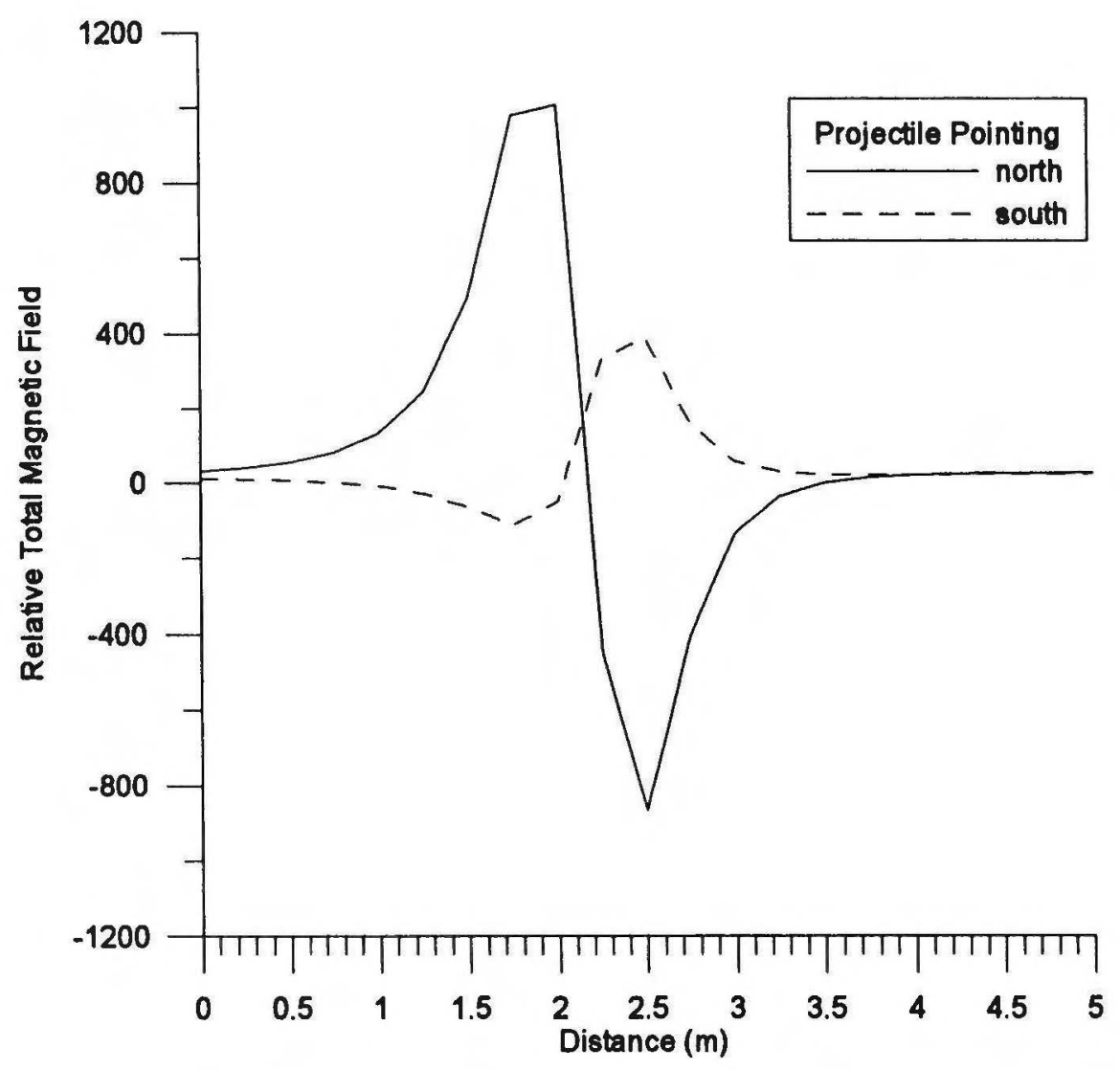

Figure 6. Profiles acquired over $105-\mathrm{mm}$ projectile with projectile pointing north and south demonstrating presence of remanent magnetization 


\section{Steel Projectile, Fired}

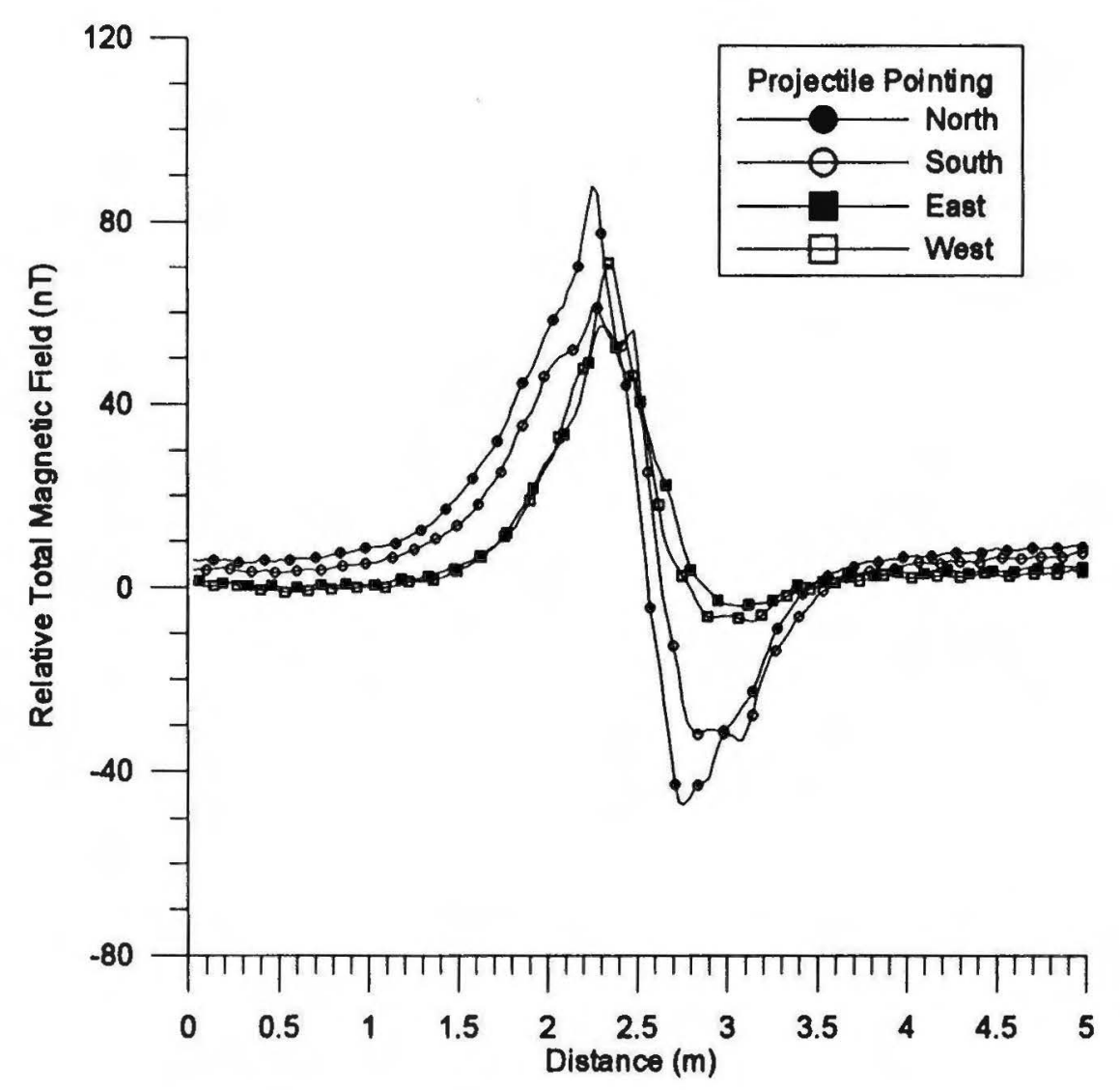

Figure 7. Example of no remanent magnetization as demonstrated by profiles acquired over a fired steel projectile 
(a)

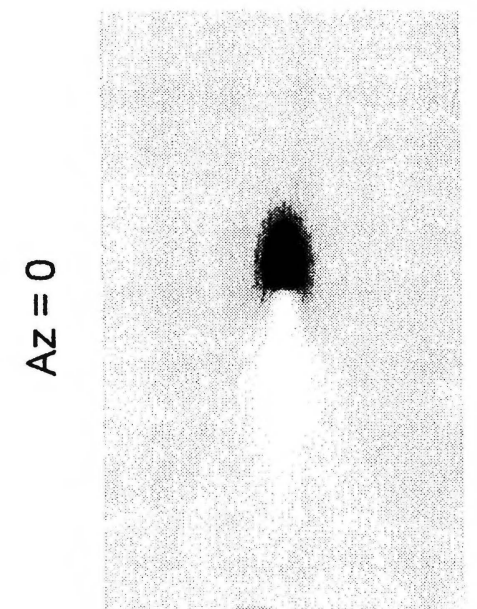

$\mathrm{Ht}$

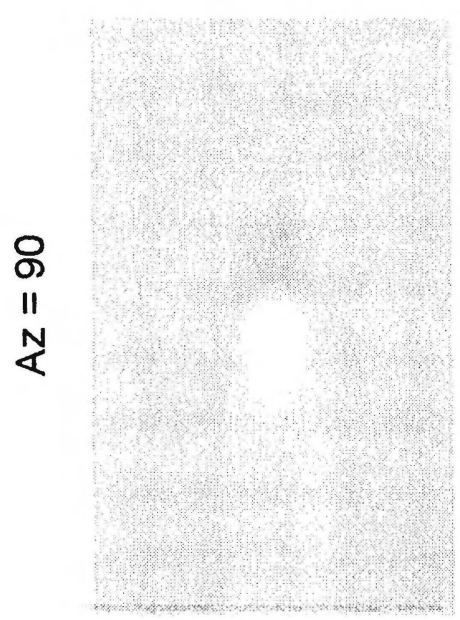

105-mm Spheroid Model

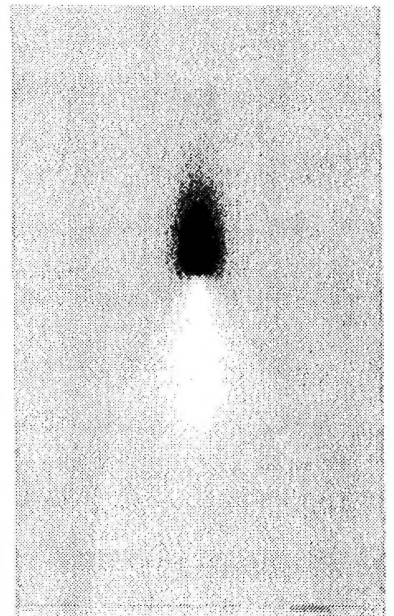

$\mathrm{H}_{7}$

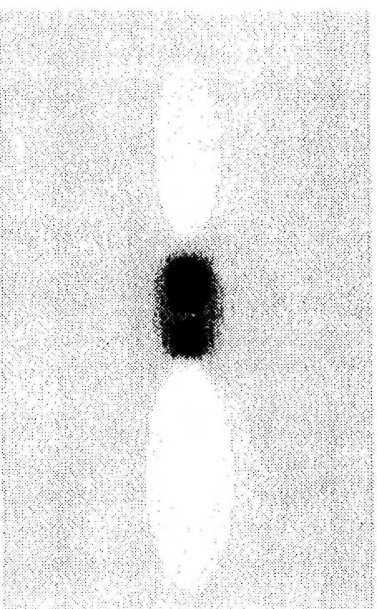

$\mathrm{Hx}$

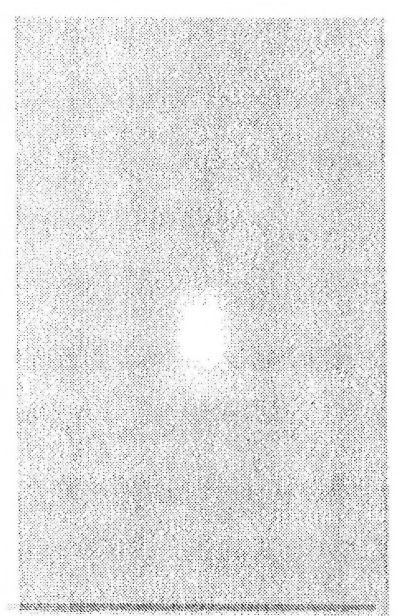

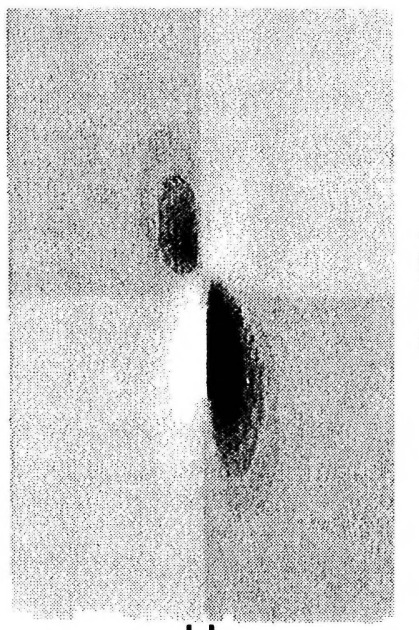

Hy

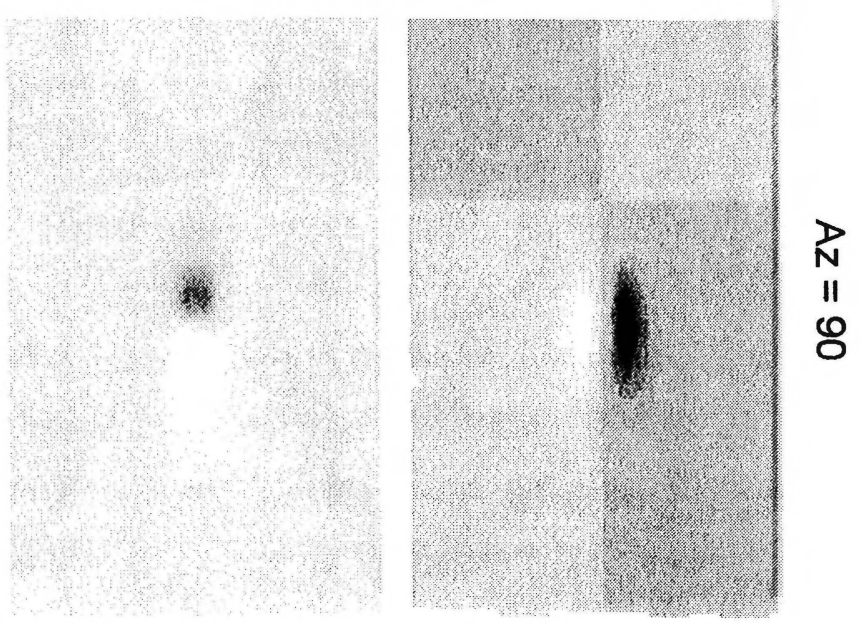

D

II

学

II

Figure 8. Image plots of the total magnetic field and individual components $\mathrm{Hx}, \mathrm{Hy}, \mathrm{Hz}$ for (a) 105-mm spheroid model and (b) 105-mm projectile field data 
(b)

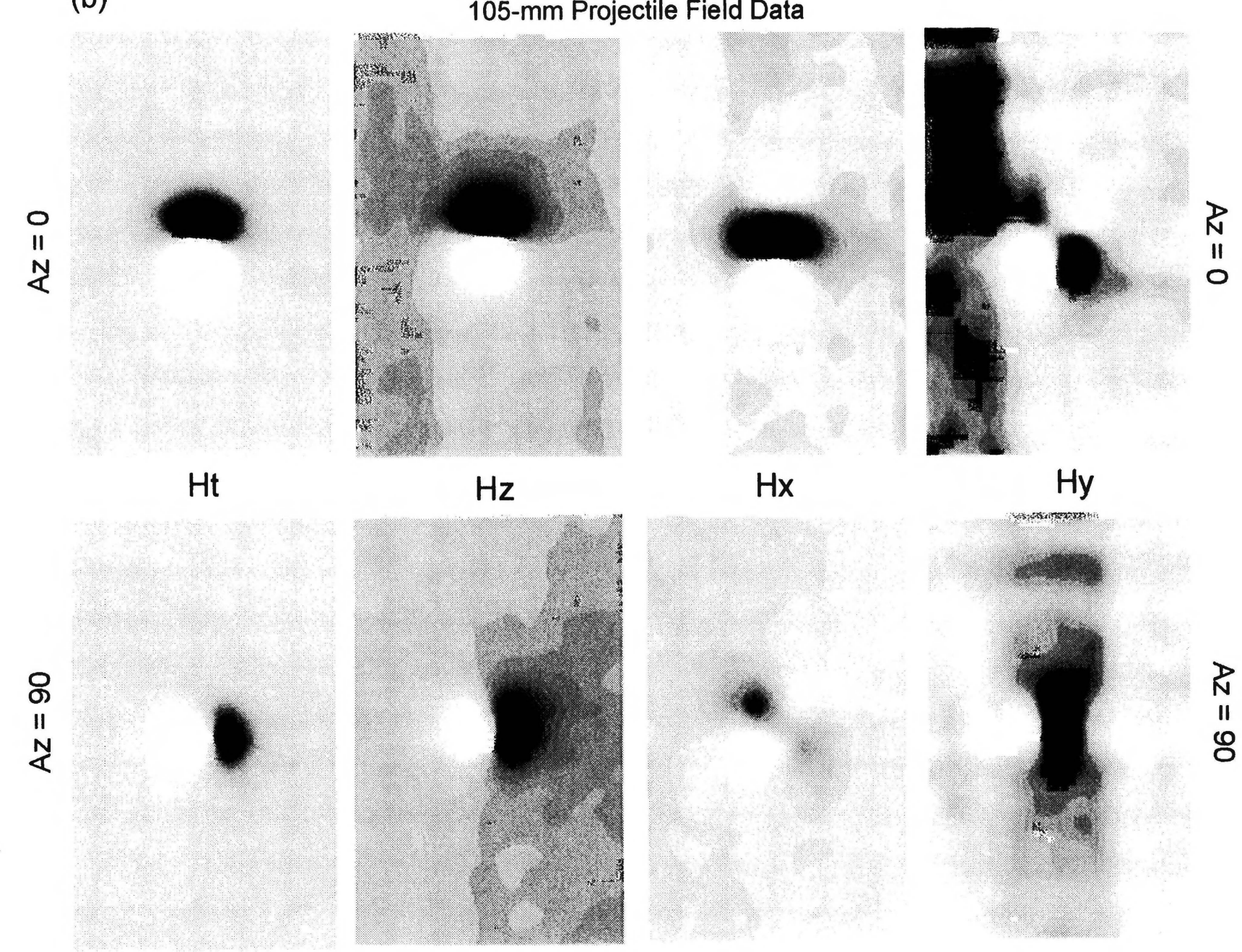

Figure 8. Concluded 
(a)

$$
\begin{gathered}
\begin{array}{c}
105-\mathrm{mm} \text { projectile, } \mathrm{Az}=0 \\
\text { Spheroid model, } \mathrm{Az}=0
\end{array} \\
\text { Profiles Along Centerline of } \mathrm{Ht} \text { Plots in Figure } 8
\end{gathered}
$$

_ fieid data $\quad .$. model data
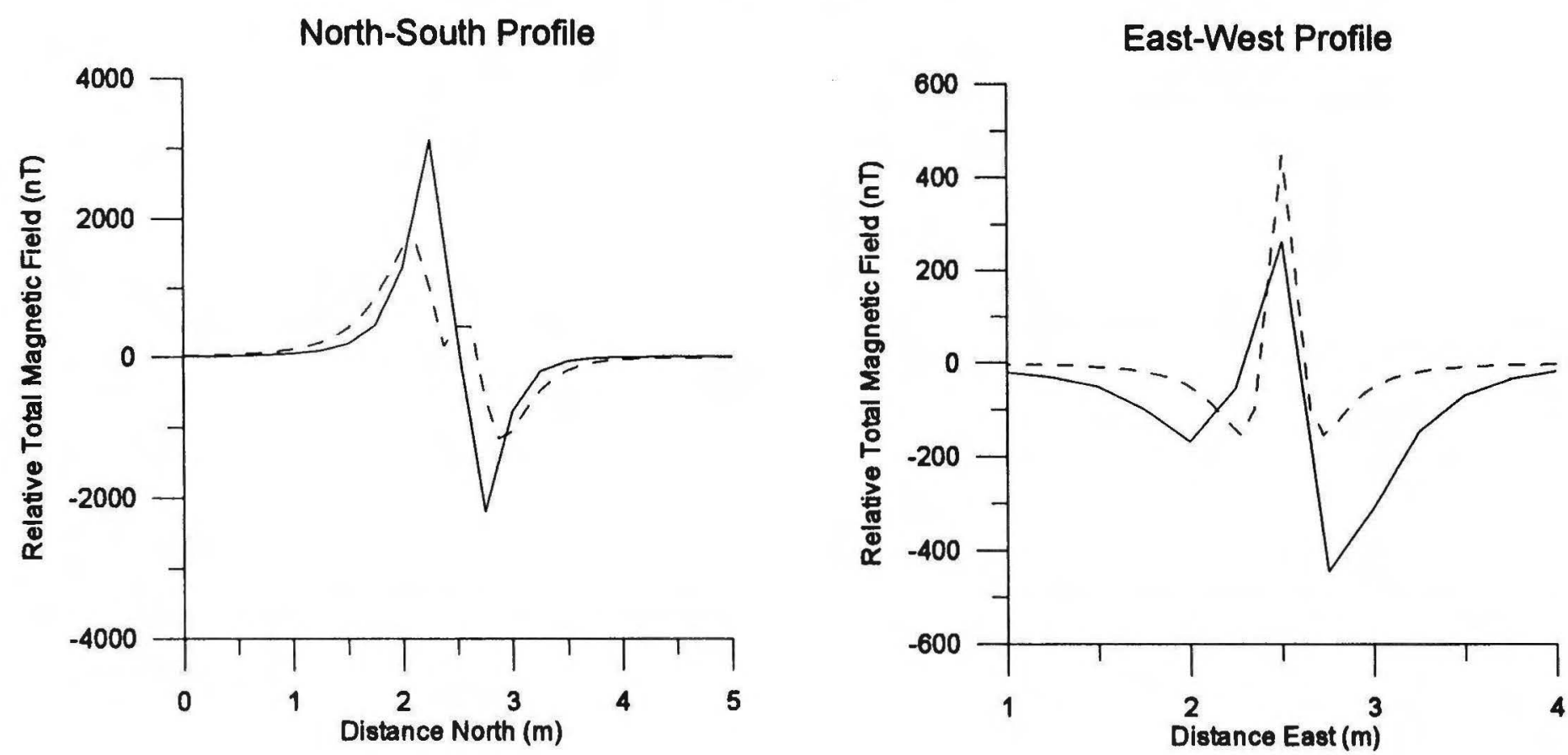

Figure 9. Comparison of total magnetic field profiles for model and field data in Figure 8. (a) $105-\mathrm{mm}$ projectile azimuth $=0$, spheroid azimuth $=0$. (b) $105-\mathrm{mm}$ projectile azimuth $=0$, spheroid azimuth $=90$. 
(b)

105-mm projectile, $A z=0$

Spheroid model, $A z=90$

Profiles Along CentertineHt Plots in Figure 8

_ field data $\quad . .-$ model date
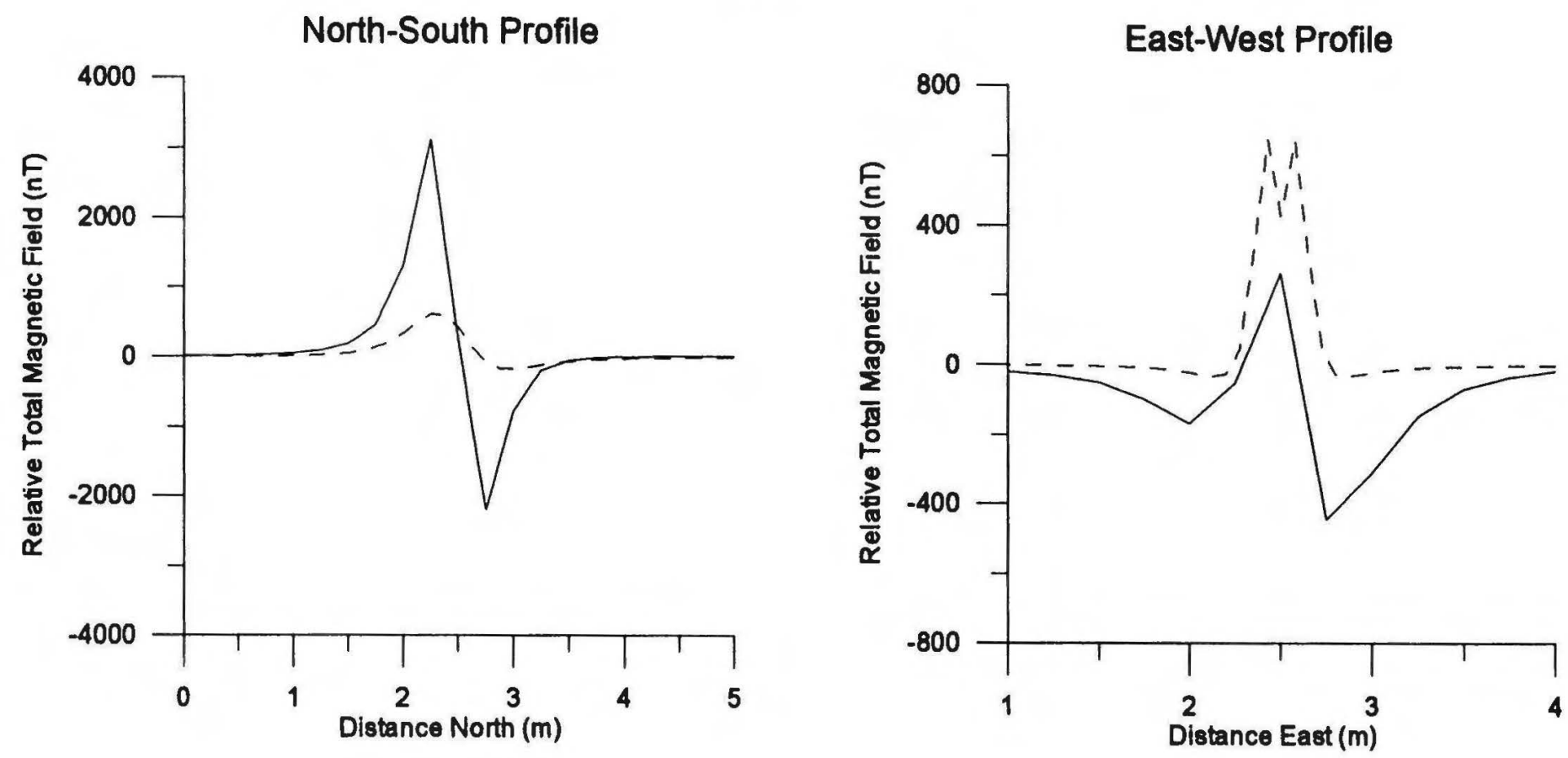

Figure 9. Concluded 
105-mm projectile, $A z=90$

Spheroid model, $A z=90$

Profiles Along Centerline of Ht Plots in Figure 8

— field data $\ldots$-..-model data
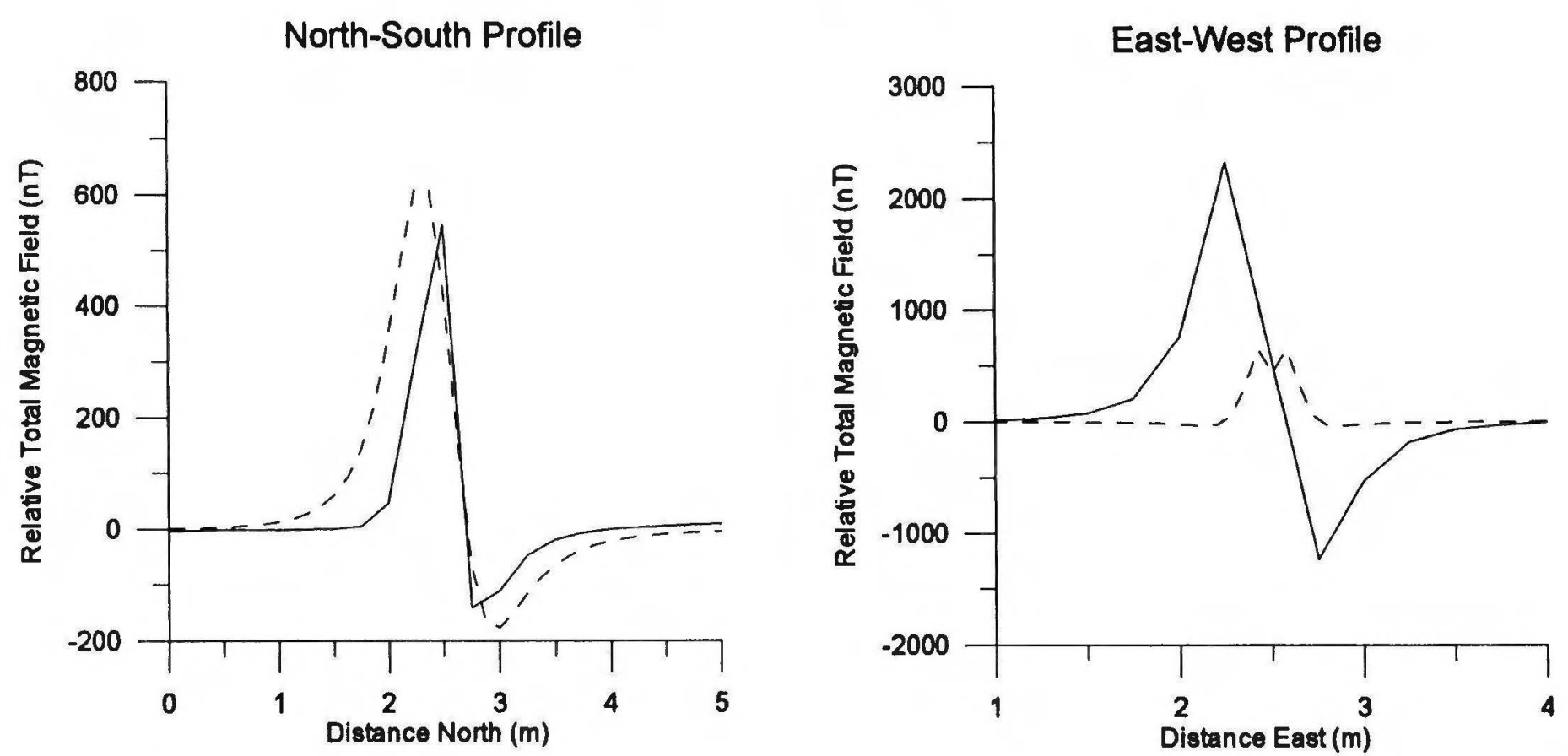

Figure 10. Comparison of total magnetic field profiles of data in Figure 8 for both model spheroid and 105-mm projectile having an azimuth of 90 

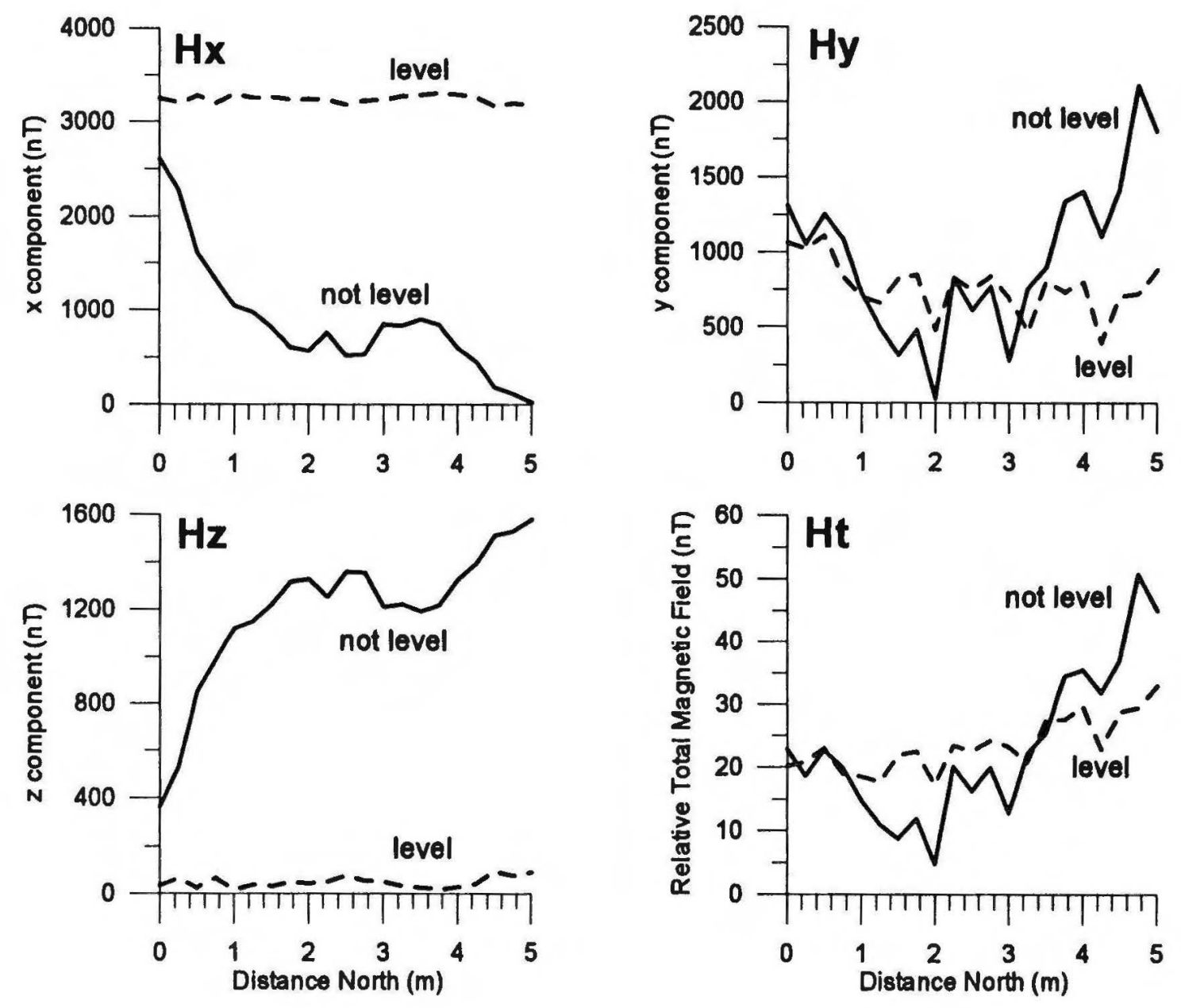

Figure 11. Comparison of total magnetic field and component data acquired when the magnetometer sensor was level and not level 


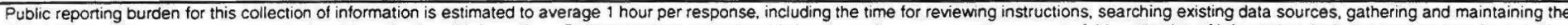

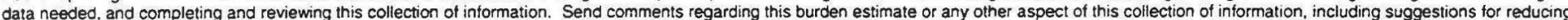

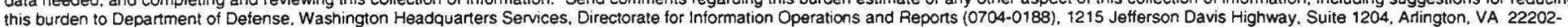

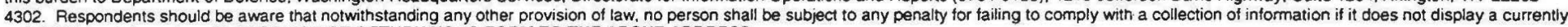
valid OMB control number. PLEASE DO NOT RETURN YOUR FORM TO THE ABOVE ADDRESS.

\begin{tabular}{l|l|l} 
1. REPORT DATE (DD-MM-YYYY) & 2. REPORT TYPE & 3. DATES COVERED (FrOM - TO)
\end{tabular}

September 2000

4. TITLE AND SUBTITLE

Final Report

Evaluation of Three-Component Magnetic Sensors for Delineation and Identification of UXO

5a. CONTRACT NUMBER

5b. GRANT NUMBER

5c. PROGRAM ELEMENT NUMBER

\section{AUTHOR(S)}

Janet E. Simms, Lewis B. Smithhart, Dwain K. Butler

5d. PROJECT NUMBER

5e. TASK NUMBER

5f. WORK UNIT NUMBER

\section{PERFORMING ORGANIZATION NAME(S) AND ADDRESS(ES)}

\section{AND ADDRESS(ES)}

U.S. Army Engineer Research and Development Center

Geotechnical Laboratory and Information Technology Laboratory

3909 Halls Ferry Road

Vicksburg, MS 39180-6199

9. SPONSORING / MONITORING AGENCY NAME(S) AND ADDRESS(ES)

Headquarters, U.S. Army Corps of Engineers

Washington, DC 20314-1000

\section{PERFORMING ORGANIZATION REPORT} NUMBER

ERDC TR-00-6

NUMBER(S)

12. DISTRIBUTION/AVAILABILITY STATEMENT

Approved for public release; distribution is unlimited.

\section{SUPPLEMENTARY NOTES}

\section{ABSTRACT}

The data acquired from three-component magnetic sensors are evaluated to determine if the information provided by the additional Hx, $\mathrm{Hy}$, and $\mathrm{Hz}$ components improves the detection, delineation, and identification of UXO. The three-component data were acquired under controlled field conditions. Model data were generated with the program MAGMOD, which uses a prolate spheriod and multipole expansion solution to estimate the induced magnetic field external to the spheriod. Comparison of the total magnetic field and individual component plots of the model and field data suggests that the three-component sensors may provide information necessary to better determine the depth and orientation (azimuth and dip) of the ordnance in the subsurface. At the present time, three-component sensors are not suitable for practicle field applications because of their sensitivity to orientation and levelness. Improper leveling of the sensor can cause a magnitude increase in the variation of the measured magnetic field.

\section{SUBJECT TERMS}

Geophysics

Magnetics

16. SECURITY CLASSIFICATION OF:

\section{a. REPORT}

UNCLASSIFIED UXO
Three-component magnetometers

b. ABSTRACT
UNCLASSIFIED

c. THIS PAGE

UNCLASSIFIED

\section{Unexploded ordnance}

17. LIMITATION
OF ABSTRACT

\begin{tabular}{|c|c|}
\hline 18. NUMBER & 19a. NAME OF RESPONSIBLE PERSON \\
\hline 32 & $\begin{array}{l}\text { 19b. TELEPHONE NUMBER (include area } \\
\text { code) }\end{array}$ \\
\hline
\end{tabular}

Standard Form 298 (Rev. 8-98)

Prescribed by ANSI Std. 239.18 


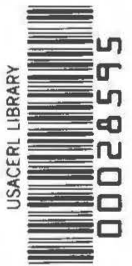

Destroy this report when no longer needed. Do not return it to the originator. 
